\title{
Numerical analysis using WRF-SBM for the cloud microphysical structures in the C3VP field campaign: Impacts of supercooled droplets and resultant riming on snow microphysics
}

\author{
Takamichi Iguchi, ${ }^{1,2}$ Toshihisa Matsui, ${ }^{1,2}$ Jainn J. Shi, ${ }^{2,3}$ Wei-Kuo Tao, ${ }^{2}$ \\ Alexander P. Khain, ${ }^{4}$ Arthur Hou, ${ }^{2}$ Robert Cifelli, ${ }^{5}$ Andrew Heymsfield, ${ }^{6}$ and Ali Tokay ${ }^{2,7}$ \\ Received 14 May 2012; revised 27 August 2012; accepted 17 October 2012; published 12 December 2012.
}

[1] Two distinct snowfall events are observed over the region near the Great Lakes during 19-23 January 2007 under the intensive measurement campaign of the Canadian CloudSat/CALIPSO validation project (C3VP). These events are numerically investigated using the Weather Research and Forecasting model coupled with a spectral bin microphysics (WRF-SBM) scheme that allows a smooth calculation of riming process by predicting the rimed mass fraction on snow aggregates. The fundamental structures of the observed two snowfall systems are distinctly characterized by a localized intense lake-effect snowstorm in one case and a widely distributed moderate snowfall by the synoptic-scale system in another case. Furthermore, the observed microphysical structures are distinguished by differences in bulk density of solid-phase particles, which are probably linked to the presence or absence of supercooled droplets. The WRF-SBM coupled with Goddard Satellite Data Simulator Unit (G-SDSU) has successfully simulated these distinctive structures in the three-dimensional weather prediction run with a horizontal resolution of $1 \mathrm{~km}$. In particular, riming on snow aggregates by supercooled droplets is considered to be of importance in reproducing the specialized microphysical structures in the case studies. Additional sensitivity tests for the lake-effect snowstorm case are conducted utilizing different planetary boundary layer (PBL) models or the same SBM but without the riming process. The PBL process has a large impact on determining the cloud microphysical structure of the lake-effect snowstorm as well as the surface precipitation pattern, whereas the riming process has little influence on the surface precipitation because of the small height of the system.

Citation: Iguchi, T., T. Matsui, J. J. Shi, W.-K. Tao, A. P. Khain, A. Hou, R. Cifelli, A. Heymsfield, and A. Tokay (2012), Numerical analysis using WRF-SBM for the cloud microphysical structures in the C3VP field campaign: Impacts of supercooled droplets and resultant riming on snow microphysics, J. Geophys. Res., 117, D23206, doi:10.1029/2012JD018101.

\section{Introduction}

[2] Microphysics of solid-phase clouds and precipitation has a very complicated structure compared to liquid-phase,

\footnotetext{
${ }^{1}$ Earth System Science Interdisciplinary Center, University of Maryland, College Park, Maryland, USA.

${ }^{2}$ Laboratory for Atmospheres, NASA Goddard Space Flight Center, Greenbelt, Maryland, USA.

${ }^{3}$ Goddard Earth Sciences Technology and Research, Morgan State University, Baltimore, Maryland, USA.

${ }^{4}$ Department of Atmospheric Sciences, Institute of Earth Sciences, Hebrew University of Jerusalem, Jerusalem, Israel.

${ }^{5}$ NOAA Earth System Research Laboratory, Boulder, Colorado, USA.

${ }^{6}$ National Center for Atmospheric Research, Boulder, Colorado, USA.

${ }^{7}$ Joint Center for Earth Systems Technology, University of Maryland, Baltimore, Maryland, USA.
}

Corresponding author: T. Iguchi, Laboratory for Atmospheres, NASA Goddard Space Flight Center, Greenbelt, MD 20771, USA.

(takamichi.iguchi@nasa.gov)

(C)2012. American Geophysical Union. All Rights Reserved. 0148-0227/12/2012JD018101 because of a great variety of the particle habits. Remotely sensed measurement of ice and snow particles often involves large uncertainty due to the various particle densities and nonsphericity. Numerical modeling of ice microphysics has difficulty in representing their complicated habits of particles and various growth mechanisms. Limited in situ measurements of aircraft or ground-based instruments are useful in order to capture the microphysical structure of clouds and precipitation and can provide important validation of numerical model experiments.

[3] Solid-phase particles are empirically classified into distinct categories such as cloud ice, snow, graupel and/or hail in a numerical modeling framework of cloud microphysics [e.g., Lin et al., 1983], according to the difference in terminal fall velocity. These models involve spontaneous autoconversion from one category to another. A few microphysical models, however, have introduced advanced approaches to cloud microphysical representations using a gradation of distinct categories: A multicomponent (water mass, solute mass and ice shape factor) bin model was 
developed using a hybrid bin method [Chen and Lamb, 1994]; ice volume was recently introduced in the methodology to represent continuous changes in the bulk density of particles [Misumi et al., 2010]. A spectral habit ice prediction system (SHIPS) that can retrain the history of particle growth by predicting particle property variables (PPVs) was developed [Hashino and Tripoli, 2007]. A conceptual model considering mass-dimension and area-dimension relationships as a continuous function of particle size and rimed mass fraction was integrated into a bulk microphysical model [Morrison and Grabowski, 2008] and into a bin microphysical model [Morrison and Grabowski, 2010]. Snow and graupel were included in the precipitation ice (PI) category using a varying rime intensity parameter in the traditional bulk microphysical parameterization [Lin and Colle, 2011; Lin et al., 2011]. Prediction of rimed mass in each of snow aggregates bins was introduced into a typical 1 moment spectral bin microphysics (SBM) to allow a smooth treatment of the transformation from snow to graupel or hail [Khain et al., 2011, 2012].

[4] The scientific goal of this study is to research the following points: Although these advanced approaches have been developed, there still remains a lack of full understanding of how ice cloud microphysics is characterized in the real atmosphere and how the numerical simulation can be optimized using the advanced microphysical approaches noted above. A comparison between numerical simulations and observational data is of considerable importance to confirm the reproducibility of the simulation and to investigate factors that lead to differences in the microphysical structure.

[5] This paper focuses on two particular snowfall events on 19-23 January 2007 observed during the field campaign of the Canadian CloudSat/Cloud-Aerosol Lidar and Infrared Pathfinder Satellite Observation (CALIPSO) Validation Project (C3VP). The campaign was conducted originally for the purpose of validating CloudSat/CALIPSO retrieval algorithm using both in situ and remotely sensed observations. The concentrated field measurements were carried out in south central Ontario, Canada from 1 October 2006 to 31 March 2007. The Center for Atmospheric Research Experiments (CARE) is the main site of the ground-based in situ and remotely sensed measurements including a lidar, radars, microwave radiometers, a spectrometer, precipitation gauges, and disdrometers. In addition, flight measurements, containing a suite of in situ and remotely sensed observations, were conducted around the CARE site.

[6] Shi et al. [2010] conducted numerical simulations of the two snowfall events using the Weather and Research Forecasting (WRF) model with a newly implemented Goddard microphysics scheme (1 moment bulk for 2 water and 3 ice classes). Their simulations successfully reproduced the radar reflectivity distributions of the snowfalls observed by the King City C-band radar measurements. The vertical cross section of the cloud structures also agreed well with corresponding CloudSat observations. The Shi et al. study mostly focused on the cloud macrophysical structures of the snowfall events using various observational data; however, the cloud microphysics was not explored in detail and remains to be fully investigated.

[7] This study utilizes a newly developed WRF coupled with spectral bin microphysics (WRF-SBM) that is identical to the microphysical part of the Hebrew University Cloud Model (HUCM) [Khain et al., 2011, 2012]. The WRFSBM is advantageous for studies involving comparison with in situ microphysical measurements, because it allows an explicit calculation of cloud particle size distributions (PSD), which are important to determine the microphysical properties of clouds and precipitation. In addition, the updated SBM can diagnoses changes of bulk density of snow aggregates by the explicit prediction of rimed mass fraction on snow. This function is of importance to investigate impacts of riming process on ice cloud microphysics.

[8] The Goddard satellite data simulator unit (G-SDSU) [Matsui et al., 2010] has been introduced to enable direct comparison between the WRF-SBM simulation and in situ or remotely sensed measurements by modulating the simulation output to be compatible with the observations. Using the G-SDSU, interactive analysis through the three components (remotely sensed, in situ measurements and model simulation) is possible to facilitate understanding of the complexities of solid-phase cloud microphysics.

[9] In this paper, the methodology including the outline of the simulation is described in section 2. The results of numerical experiments and comparison with measurements are discussed in section 3 . The summary and conclusions are given in section 4 .

\section{Methodology}

\subsection{Description of the WRF-SBM}

[10] The WRF model is a regional numerical weather prediction (NWP) system principally developed by the National Center for Atmospheric Research (NCAR) in collaboration with several research institutions in U.S. The WRF has two types of dynamical solvers: One is the Eulerian mass solver referred to as the Advanced Research WRF (ARW). The other is the Nonhydrostatic Mesoscale Model (NMM) developed by the National Centers for Environmental Prediction (NCEP). The ARW version 3.1.1 is employed in this study with the following physical options: The eta surface layer scheme based on similarity theory [Monin and Obukhov, 1954] is used to calculate the surface boundary layer dynamics, and Mellar-YamadaJanjic Level 2.5 turbulent closure model [e.g., Janjić, 1990] is employed to calculate the planetary boundary layer (PBL) process. The Noah land surface model with a four-layer soil is applied to provide heat and moisture fluxes over land surface. The updated Goddard radiation package for both longwave and shortwave radiations is used to compute atmospheric heating and cooling rate profiles and surface energy budget.

[11] The WRF ARW version 3.1.1 was coupled with the SBM part of the HUCM [Khain et al., 2011]. This version of SBM is the full package that is different from the Fast-SBM described by Lynn et al. [2005a, 2005b] and Khain et al. [2009, 2010]. Cloud hydrometeors are categorized into one-water and six-ice classes, that is, water droplets, ice crystals (plate, column, dendrite), snow aggregates, graupel, and hail. The discrete PSDs of the hydrometeor classes are represented on a grid containing 43 doubling mass bins covering particles mass sizes in a range of $3.35 \times 10^{-11}$ $\mathrm{g}<$ mass $<1.47 \times 10^{2} \mathrm{~g}(2 \mu \mathrm{m}<$ radius $<32.8 \mathrm{~mm}$ in terms of the radii of droplets or melted ice). The relationships 
(a)

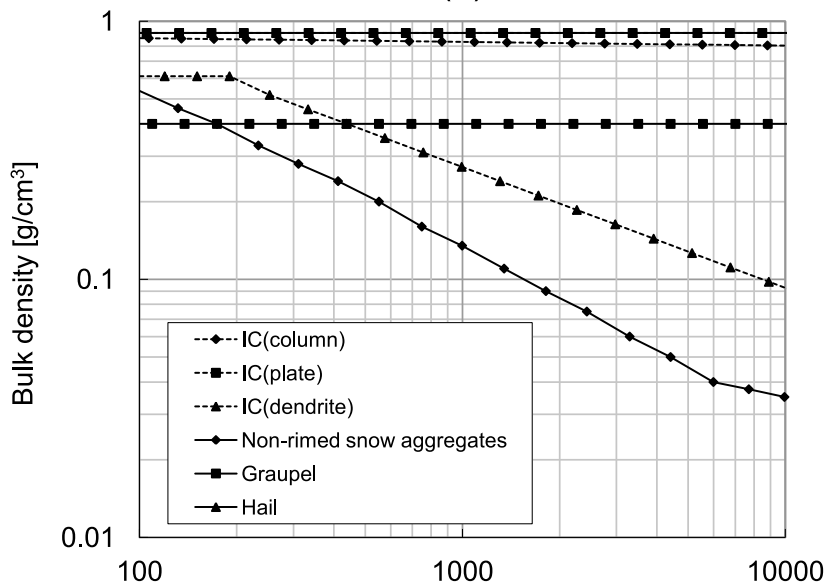

radius of mass equivalent sphere with the bulk density [um]

(b)

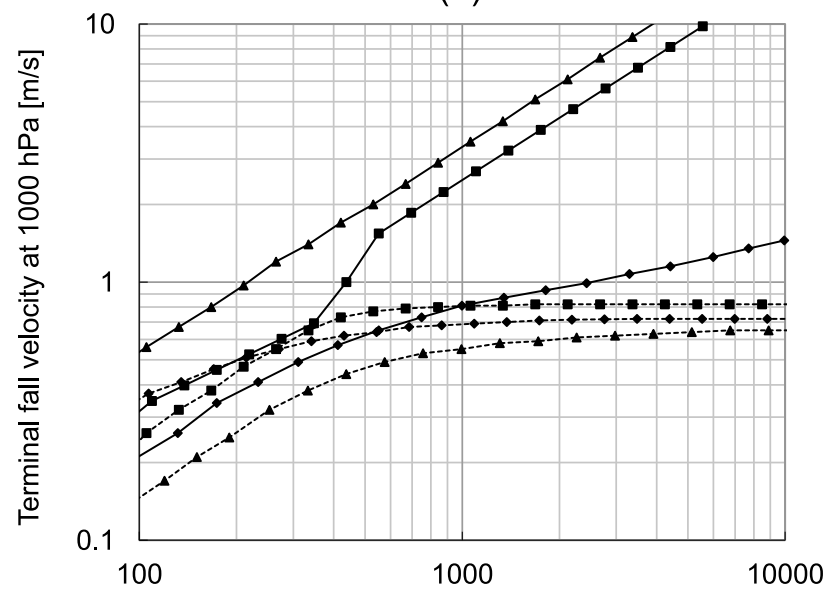

Radius of mass equivalent sphere with the bulk density [um]

Figure 1. Relationships (a) between the particle bulk densities and radii of mass equivalent sphere with the bulk density and (b) between the terminal fall velocity at $1000 \mathrm{hPa}$ and radii of mass equivalent sphere with the bulk density assumed in the spectral bin microphysical model.

between the particle bulk densities and radii of mass equivalent sphere with the bulk density assumed in the SBM are shown in Figure 1a. Snow aggregates, graupel, and hail are assumed to be fluffy spheres when calculating their microphysical processes [Khain and Sednev, 1995]. The supplementary mass size distributions representing a liquid part on melting ice particles and a rimed part on snow aggregates are also added into the sets of 43 bins. The size distribution of condensation nuclei $(\mathrm{CN})$ is discretized into a mass grid containing 13 bins with a radius range from $10^{-3}$ $\mu \mathrm{m}$ to $1 \mu \mathrm{m}$. The use of a smaller number of $\mathrm{CN}$ bins than that of the original HUCM SBM is to improve the efficiency of computation [Iguchi et al., 2008].

[12] The SBM calculates nucleation of droplets and ice crystals, including condensation and deposition growth, evaporation, sublimation, droplet freezing, riming, melting, shedding, coalescence growth, and breakup of the categorized hydrometeor particles. The nucleation of droplets is calculated on the basis of the Köhler equation using grid-scale supersaturation with respect to water. All $\mathrm{CN}$ lager than critical radius determined by the supersaturation value is assumed to be converted to cloud droplets of the radius that is determined by the equation.

[13] The formation processes of ice crystals are divided into homogenous and heterogeneous nucleation and ice multiplication. The heterogeneous nucleation is further classified into four types: deposition, condensation-freezing, immersion-freezing and contact-freezing nucleation [Rogers and Yau, 1989]. The SBM explicitly calculates ice multiplication [Hallett and Mossop, 1974] and heterogeneous nucleation, except for contact-freezing nucleation. Contactfreezing nucleation is neglected in the present model because of their lower production efficiencies [Khain et al., 2000]. A number concentration of ice nuclei (IN) is not treated as an explicit prognostic variable, but its function is implicitly parameterized. The equation of Meyers et al. [1992] for deposition and condensation-freezing nucleation is used to calculate a newly generated number of primary ice crystals at each time step; the diagnostic equation is formulated into the time integration using a semi-Lagrangian approach [Khain et al., 2000]. The type of generated ice crystal is dependent on the environmental temperature [Takahashi et al., 1991]. Immersion-freezing nucleation is calculated using two types of parameterizations: When the ambient temperature is higher than $235.15 \mathrm{~K}$, the probability of freezing for supercooled droplets is calculated on the basis of the parameterization of Ovtchinnikov and Kogan [2000]. Otherwise, the parameterization by Bigg [1953] is used to provide the probability of freezing of supercooled droplets. Homogenous nucleation, that is, homogenous droplet freezing, is currently included in the Bigg's parameterization.

[14] Condensation, deposition, evaporation, and sublimation are calculated using the solution proposed by Khain et al. [2008]. A flux method of Bott [1998] is employed for solving the stochastic collection equation to determine the coalescence growth. This scheme is diffusive and hence the particle number concentration and the mixing ratio are potentially underpredicted [Connolly et al., 2012]; the problem should be improved in future work. The collision efficiencies are given from the studies of $J i$ and Wang [1990], Wang and Ji [1997], Pruppacher and Klett [1997], Pinsky et al. [2001], Khain et al. [2001], and Khain et al. [2004]. Gravitational sedimentation is calculated using a box-Lagrangian drop scheme [Kato, 1995]. The terminal fall velocities are given from the studies of Beard [1976], Pruppacher and Klett [1997], and Khain et al. [2001]. Gradual melting of snow aggregates, graupel and hail and shedding of water from melting graupel and hail are calculated using the supplementary size distribution of liquid mass inside the particles; the methodology of the calculation follows Rasmussen and Heymsfield [1987] and Phillips et al. [2007].

[15] Note that the SBM can explicitly calculate changes of bulk density and resultant bulk radius of snow aggregates using the supplementary mass size distribution of rimed part in each mass bin at every time step. If the bulk density of aggregates with bulk radius larger than $550 \mu \mathrm{m}$ exceeds $0.2 \mathrm{~g} / \mathrm{cm}^{3}$, the content of the bin is moved into the same 
mass bin of graupel. In addition, if the rimed mass fraction of aggregates with bulk radius larger than $550 \mu \mathrm{m}$ is over $90 \%$, the similar migration to graupel then hail occurs. The terminal fall velocities and the collision kernels of snow aggregates are corrected at any time according to changes of the bulk density and radius. The terminal velocities of rimed aggregates are calculated by a liner interpolation between the values of nonrimed snow aggregate and hail. The collision kernels are recalculated using the modified radii as well as terminal fall velocities.

\subsection{Setup of Numerical Experiments}

[16] Two particular snowfall events from 19 to 23 January 2007 are the focus of this study; the first and second events are referred as to lake-effect snowstorm and synoptic snowfall, respectively, according to Shi et al. [2010]. Two $36 \mathrm{~h}$ individual integrations were conducted from 12:00 UTC on 19 January to 00:00 UTC on 21 January, and 12:00 UTC on 21 January to 00:00 UTC on 23 January. Three simulation domains were constructed with horizontal grid intervals of 9,3 , and $1 \mathrm{~km}$ and corresponding grid components of $301 \times 241,430 \times 412$, and $457 \times 457$ for the d01, d02, and d03 domains following those in the work of Shi et al. [2010, Figure 4]; the inner domain d 03 is centered at $44.0^{\circ} \mathrm{N}, 80.7^{\circ} \mathrm{W}$. The vertical domain, extending to a height of approximately $20 \mathrm{~km}$ was divided into 60 layers with intervals increasing with altitude.

[17] First, the domain d01 is individually simulated using the initial and lateral boundary conditions from the analysis data sets of the North America Mesoscale model forecast (NAM) 218 AWIPS grids; the data sets are distributed by NCEP with $12 \mathrm{~km}$ horizontal grid intervals, 40 vertical levels and 4 samples per day. The one-moment bulk microphysics of Goddard Cumulus Ensemble model (GCE) [Tao and Simpson, 1993; Tao et al., 2003; Lang et al., 2007] is employed in this domain, together with the Grell-Devenyi ensemble cumulus parameterization [Grell and Devenyi, 2002]. The 3ICE-graupel option [Tao et al., 2003] including cloud water, rain, cloud ice, snow, and graupel is selected.

[18] Second, the domains d02 and d03 are simulated at the same time using online two-way nesting; all prognostic variables are common between domains d02 and d03 in the online two-way nesting configuration. An offline one-way nesting is applied to connect the domain $\mathrm{d} 02$ to the parent domain $\mathrm{d} 01$. No hydrometeor advection is considered between domains $\mathrm{d} 01$ and $\mathrm{d} 02$ in the one-way nesting configuration. The initial conditions of $\mathrm{d} 02$ and $\mathrm{d} 03$ are given from the analysis data sets of the NAM 218 AWIPS grids. The fully packaged SBM is employed in both domains d02 and d03 without a subgrid cumulus parameterization. The initial $\mathrm{CN}$ concentration field is uniform in the layer under a height of $2 \mathrm{~km}$ and decreases exponentially with a scale height of $2 \mathrm{~km}$ above $2 \mathrm{~km}$. The initial $\mathrm{CN}$ size distribution is set using an empirical relationship between the number concentration of cloud condensation nuclei $(\mathrm{CCN})$ and supersaturation with respect to water [Khain et al., 2000, equations 2.4 and 2.6]:

$$
\frac{d N}{d(\ln r)}=1.5 N_{0} k S^{k}=1.5 N_{0} k\left(\frac{4 A^{3}}{27 r^{3} B}\right)^{k / 2}
$$

where $N_{0}$ and $k$ are the parameters that determine the concentration and the soluble fraction of $\mathrm{CN}$ in the assumed air mass. $N_{0}=1500 \mathrm{~cm}^{-3}$ and $k=0.5$ were set in this experiment; these values were selected by consideration of the local environment of continental area near the lakes [e.g., Pruppacher and Klett, 1997; Khain et al., 2010]. $A$ and $B$ are the coefficients in the Köhler equation [e.g., Rogers and Yau, 1989] considering the Kelvin effect and Raoult's Law, respectively. Zero horizontal gradient was set for the inflow case in the lateral boundary region of domain $\mathrm{d} 02$ to prevent cleanup of $\mathrm{CN}$ by incoming advection.

\subsection{Goddard Satellite Data Simulator Unit}

[19] The G-SDSU is an off-line module unit to convert output of atmospheric model simulation into the variables that correspond to primary products of various measurements. The output can be used for the evaluation of simulations through direct comparison with low-level measurement products [Matsui et al., 2009; Masunaga et al., 2010]. This approach for comparison between simulations and measurements has the following advantage: Retrieval algorithms generally include some assumptions to make geophysical parameters from the raw products. The assumptions are often in disagreement with those used in the atmospheric model. This inconsistency can make the comparison unreliable, when the geophysical parameters derived from the retrieval and simulation are compared. However, the direct comparison using the simulator unit can bypass the problem, because the assumptions in the simulator unit are consistent with those made in the atmospheric model.

[20] The G-SDSU is run off-line and coupled with the WRF-SBM directly to make use of simulated PSDs of hydrometeors and rimed mass size distribution of snow aggregates. Although many kinds of measurement activities were conducted in the C3VP field campaign, this study has mostly focused on the observational data sets of King City C-band radar, NRC Convair 580 aircraft and ground-based in situ instruments at CARE site. The methods to calculate the primary products from the WRF-SBM simulation are explained in section 3, together with an analysis of the comparative results.

\section{Results}

\subsection{Analysis of the Macro Profiles Using C-Band Radar Data}

[21] The King City $5.5 \mathrm{GHz}$ C-band dual-polarization radar is located at $43.96^{\circ} \mathrm{N}, 79.57^{\circ} \mathrm{W}, 30 \mathrm{~km}$ from the CARE site $\left(44.23^{\circ} \mathrm{N}, 79.78^{\circ} \mathrm{W}\right)$. During C3VP campaign, the radar performed it's normal operation scan strategy, collecting multiple tilt data every $10 \mathrm{~min}$. Special single tilt scans tailored to $\mathrm{C} 3 \mathrm{VP}$ requirements were inserted into the sequence; however, for the purpose of this study only the multiple tilt data were used. The details of the radar characteristics can be found in the work of Hudak et al. [2006] and Huang et al. [2010]. Subsequent to quality control procedures, the scanning radar reflectivity was interpolated to a three-dimensional Cartesian coordinate grid with a $200 \mathrm{~km}$ domain extending north-south and east-west. The grid resolution was $1 \mathrm{~km}$ and $500 \mathrm{~m}$ in the horizontal and vertical, respectively. This study used only gridded copolarized radar reflectivity. The reflectivity data is processed 
to compute the maximum reflectivity $\left(\mathrm{Z}_{\max }\right)$ and $0 \mathrm{~dB}$ echotop height $\left(\mathrm{H}_{\mathrm{et}}\right)$.

[22] The corresponding product of the C-band radar is calculated using the output of the WRF-SBM simulation through G-SDSU. The methodology to calculate radar reflectivity in the G-SDSU is based on that of Masunaga and Kummerow [2005]. The backscattering cross section of particles is calculated on the basis of the full solution of Mie-based routine with dialectic constant through the Maxwell-Garnet assumption (ice inclusion with air matrix) and assuming the particles to be a spherical body with the particle density and size assumed in the SBM for each mass bin. The spherical assumption is highly appropriate to the calculation of the microwave frequency range (C-band) in Rayleigh regime [Liu, 2008].

[23] Figures 2 and 3 show the spatial distributions of $Z_{\max }$ and $\mathrm{H}_{\mathrm{et}}$ for the lake-effect and synoptic events in the form of snapshots at $00 \mathrm{Z}, 06 \mathrm{Z}$ and $12 \mathrm{Z}$ on 20 and 22 January. The observed $Z_{\max }$ patterns of the both events (Figures 2a and $2 \mathrm{c}$ ) correspond reasonably well to those calculated from the WRF-SBM simulations through the G-SDSU radar simulator (Figures $2 \mathrm{~b}$ and $2 \mathrm{~d}$ ). In the lake-effect case, an isolated intense snowband was triggered by the passage of a cold front over Lake Huron. Cold dry air blowing across the lake accentuated the heat and moisture fluxes from the relatively warm water surface of the lake, and formed the snowband on the leeward shore. At $00 \mathrm{Z}$ on 20 January, the formation of the lake-effect snowbands with $\mathrm{H}_{\mathrm{et}}$ of approximately $2 \mathrm{~km}$ was observed in both the observational data and simulation in the vicinity of Geogian Bay of Lake Huron. At 06Z, both the observation and simulation show two snowbands extending northwest-southeast, though the locations of simulated bands are mismatched to the radar observations. At $12 \mathrm{Z}$, one snowband in the vicinity of Georgian Bay remained. The magnitude of $Z_{\max }$ is approximately $25 \mathrm{~dB}$ in both the simulation and observations and is distributed almost uniformly from $00 \mathrm{Z}$ to $12 \mathrm{Z}$.

[24] In contrast to the lake-effect case (20 January), the precipitation system on 22 January was synoptically driven with widespread moderate snowfall caused by the passage of synoptic low-pressure system. At $00 \mathrm{Z}$ and $06 \mathrm{Z}$ on 22 January, a relatively homogenous $Z_{\max }$ distribution covered almost the entire domain of the snapshot. At $12 \mathrm{Z}$, the observation showed an end of precipitation as the system moved eastward, whereas the simulation indicated the persistence of weak radar echo at this time. The $Z_{\max }$ in the synoptic event ranges from approximately $15 \mathrm{~dB}$ to $25 \mathrm{~dB}$ and $\mathrm{H}_{\mathrm{et}}$ is approximately $5 \mathrm{~km}$ with the exception of $12 \mathrm{Z}$, where the $\mathrm{H}_{\mathrm{et}}$ is notably lower as the system decayed. Note that the circular pattern with low $\mathrm{H}_{\mathrm{et}}$ around the center of plots at $00 \mathrm{Z}$ and $06 \mathrm{Z}$ in Figure $3 \mathrm{c}$ is an artifact of the interpolation process with the limited vertical elevation angle of the ground radar.

[25] The comparison of the snapshots in Figures 2 and 3 shows some forecast errors for the location and timing of both systems. This kind of error is often controlled by initial and boundary conditions rather than the model physics. A quantitative analysis that does not depend on location and timing can be useful to compare the overall structures of the observed and simulated precipitation systems. Figure 4 shows a statistical comparison in the form of joint altitudereflectivity contoured frequency diagrams, illustrating the overall probability density for both the altitude and reflectivity. The data accumulated from $22 \mathrm{Z}$ on 19 January to $12 \mathrm{Z}$ on 20 January for the lake-effect case and from $00 \mathrm{Z}$ to $12 \mathrm{Z}$ on 22 January for the synoptic case over the domain of $200 \mathrm{~km}$ square centered at the radar is sampled to make the statistical plots. The areas with radii of $15 \mathrm{~km}$ in the lakeeffect case and $40 \mathrm{~km}$ in the synoptic case around the radar are not included to remove the effect of the limited vertical sampling of the radar and the subsequent impact on the Cartesian interpolation.

[26] The simulation plots share common characteristics with those of the radar observations and show the difference in the profiles between the two events (Figure 4). The probability distributions are limited in the vertical to altitudes below $3 \mathrm{~km}$ and encompass a wide range of radar reflectivity $(30 \mathrm{~dB})$ in the lake-effect case. In contrast, the corresponding distributions extend over $4 \mathrm{~km}$ in depth and are slightly narrower with maximum reflectivities less than $30 \mathrm{~dB}$ in the synoptic case. Together with the analysis of Figures 2 and 3, the lake-effect event is characterized as a localized small height and intense snowstorm, derived principal from lake-effect processes, whereas the synoptic event is characterized as a widely distributed, relatively high-up with moderate snowfall.

[27] In the lake-effect case, the simulated probability distribution is biased to the lower values relative to the radar observations in terms of both altitude and reflectivity. This is considered to be due to limitations of both the measurements and simulation. The radar coverage area is generally at an elevation of several hundred meters, and the Blue Mountains $\left(44.5^{\circ} \mathrm{N}, 80.4^{\circ} \mathrm{W}\right)$ with the maximum terrain height of approximately $550 \mathrm{~m}$ is located near the southern side of Geogian Bay (approximately $90 \mathrm{~km}$ from the King radar). Because the lowest elevation angle utilized in the King City radar data is $0.3^{\circ}$, the height of the radar beam is at an approximate elevation of $1.2 \mathrm{~km}$ above ground level at this range. Therefore, there is some uncertainly in measuring and interpolating reflectivity at the lowest heights shown in Figure 4. Yet, the simulation still underestimates the height of the system as illustrated in Figures $3 \mathrm{a}$ and $3 \mathrm{~b}$. The observed echo-top height is approximately $1 \mathrm{~km}$ taller than that of the simulation. The similar shallow bias of the simulated snowband is also reported by Shi et al. [2010].

[28] In the synoptic case, the simulated distribution is in overall better agreement with the observed pattern, though the simulated distribution is slightly biased to lower reflectivities and higher altitudes compared to the radar. We speculate that these small biases are due to forecast errors that are caused by imperfect initial and boundary conditions and not removed in the quantitative analysis because of the limitation of sampling. The magnitude of probability density is underpredicted, because the distribution profile of the simulation is wider in the vertical compared to the radar observations. In contrast, the magnitude of the simulated probability density is overpredicted in the lake-effect case because the simulated distribution is narrower in the vertical compared to the observation distribution.

[29] Observations at the CARE site showed a distinct difference in the surface precipitation amount between the two events. Approximately $12.3 \mathrm{~mm}$ and $2.4 \mathrm{~mm}$ of liquid water equivalent (LWE) $24 \mathrm{~h}$ accumulated surface precipitation were measured on 20 (lake-effect case) and 22 Jan. 


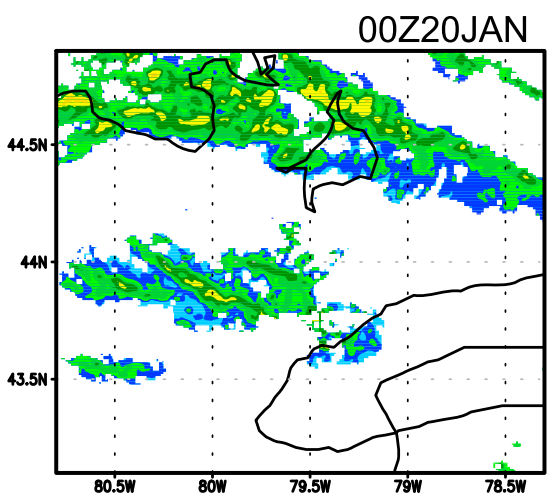

a) Lake-effect, measurement
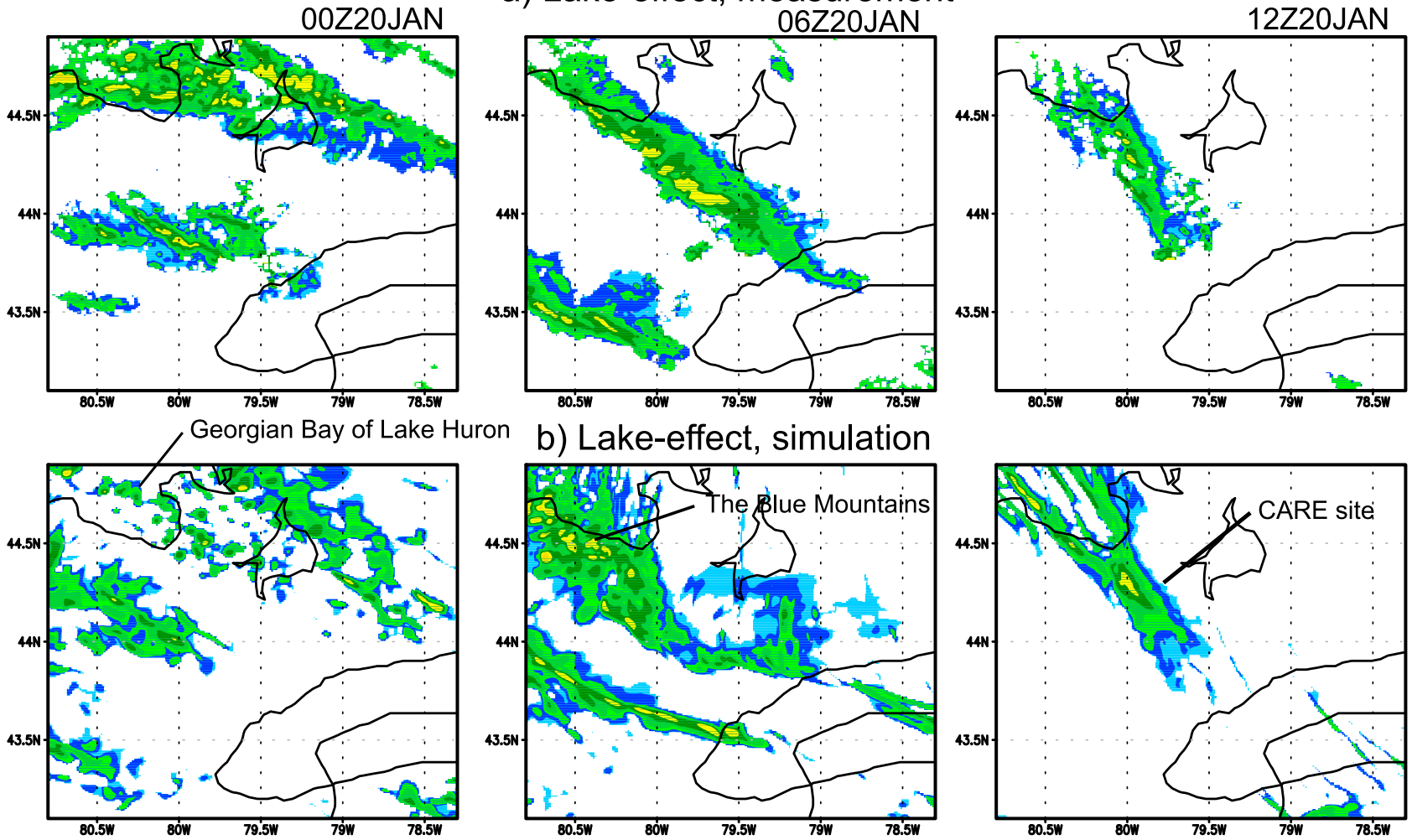

b) Lake-effect, simulation
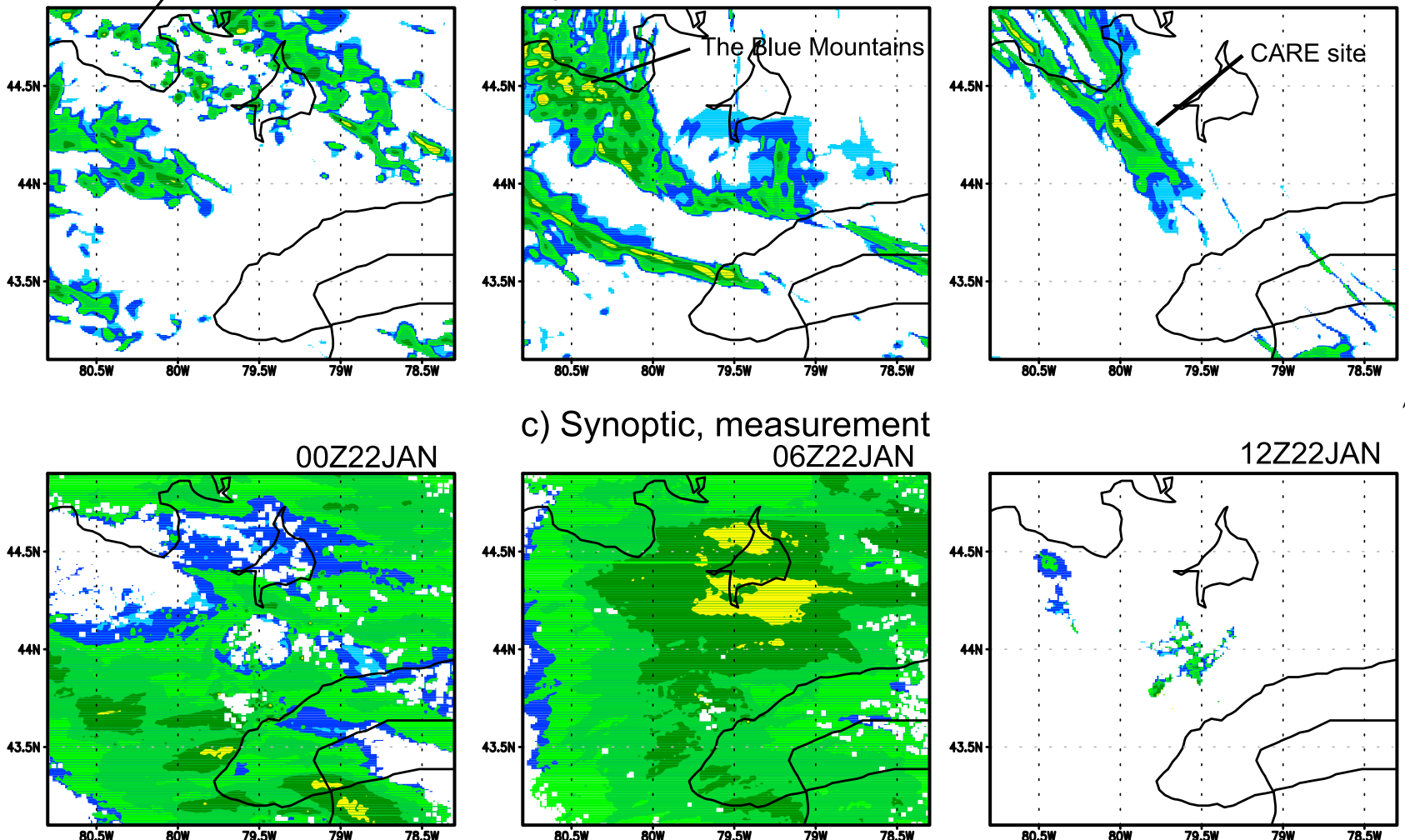

c) Synoptic, measurement
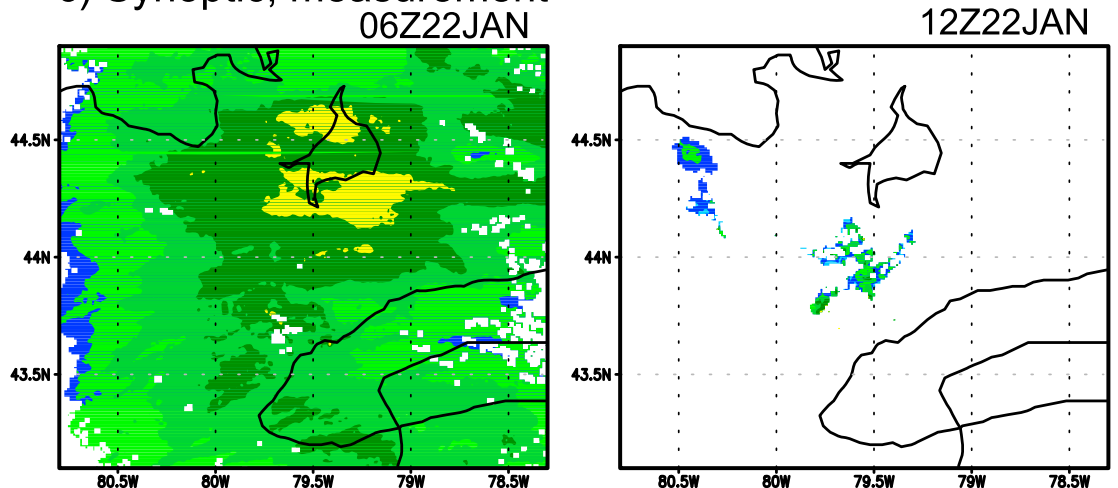

d) Synoptic, simulation
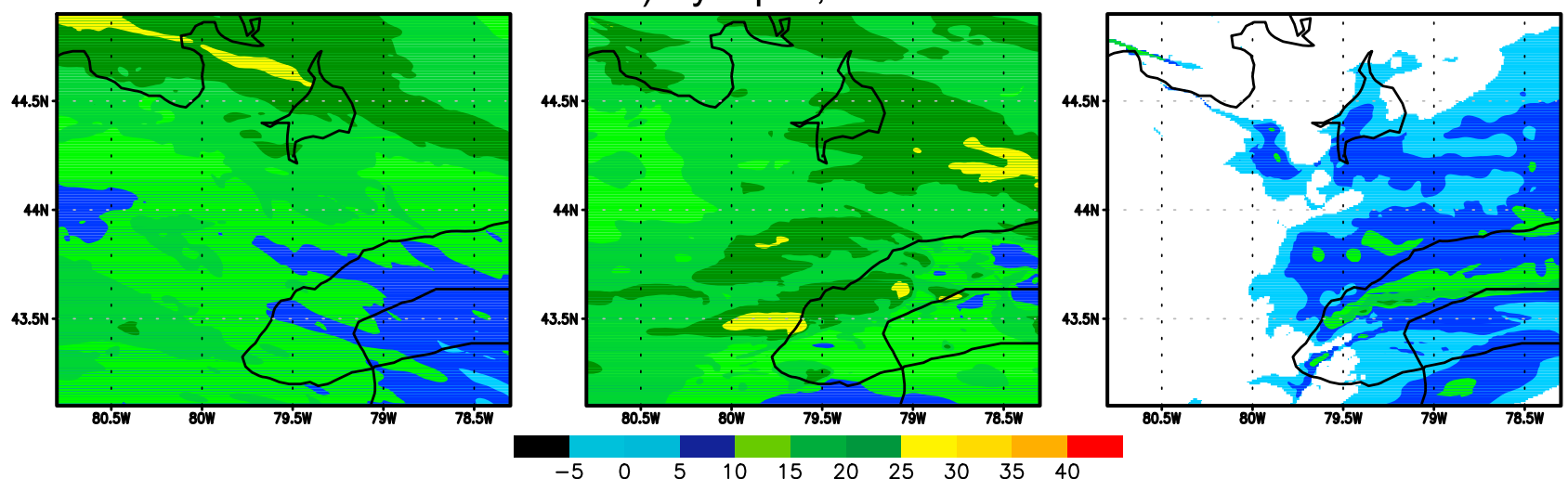

Figure 2. Snapshots of horizontal distributions of vertically maximum C-band radar reflectivity (dB) $(a, c)$ derived from King City radar measurement and (b, d) simulated by Weather Research and Forecasting model coupled with a spectral bin microphysics (WRF-SBM). 


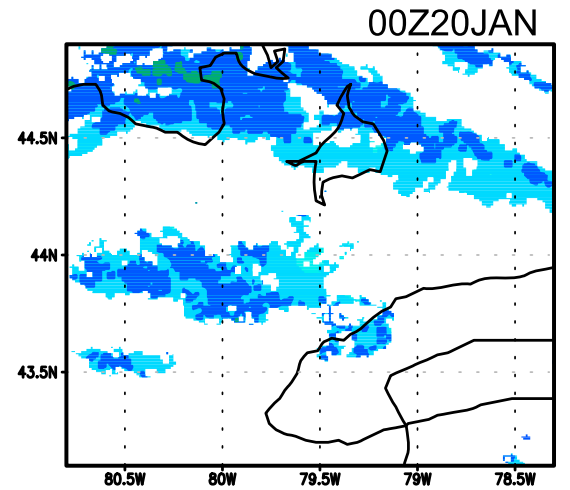

a) Lake-effect, measurement
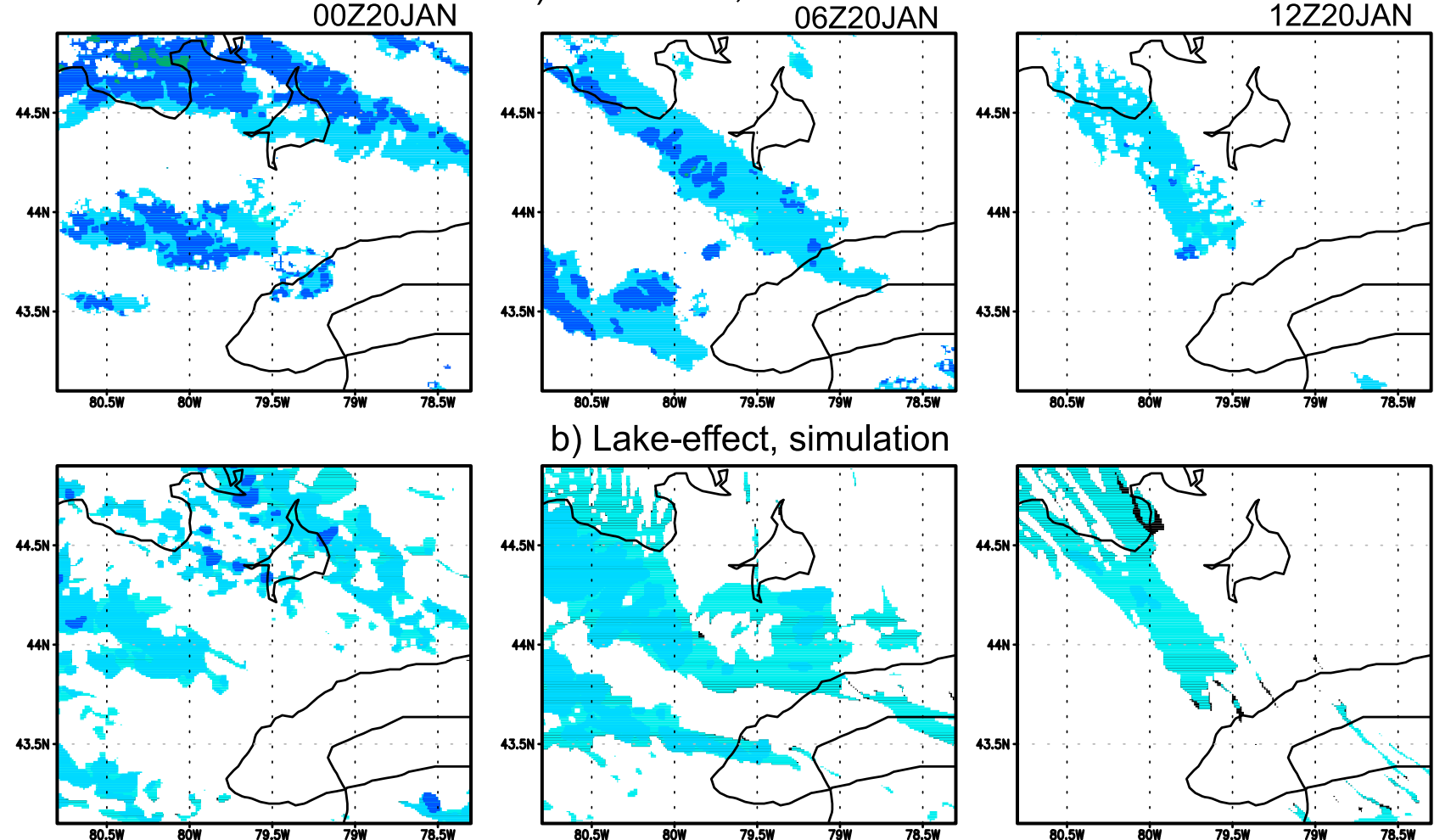

b) Lake-effect, simulation
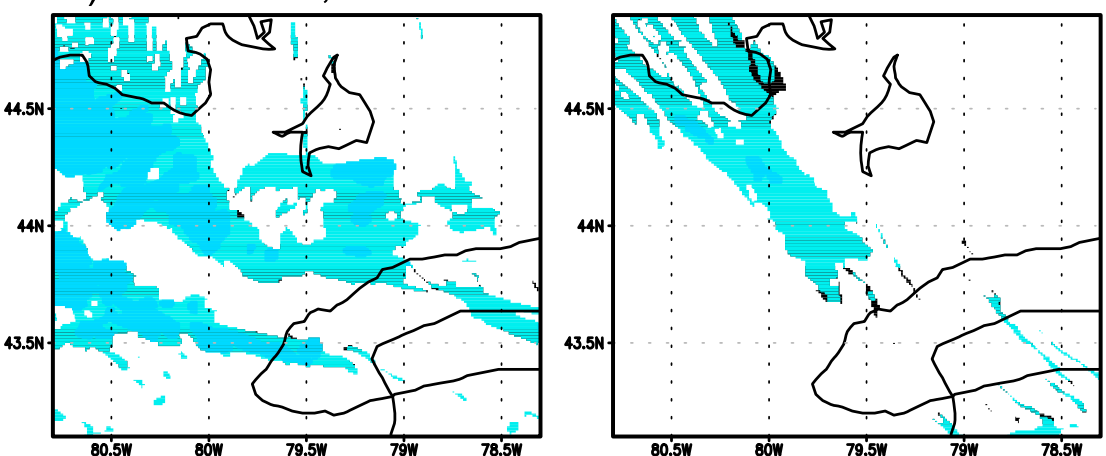

c) Synoptic, measurement
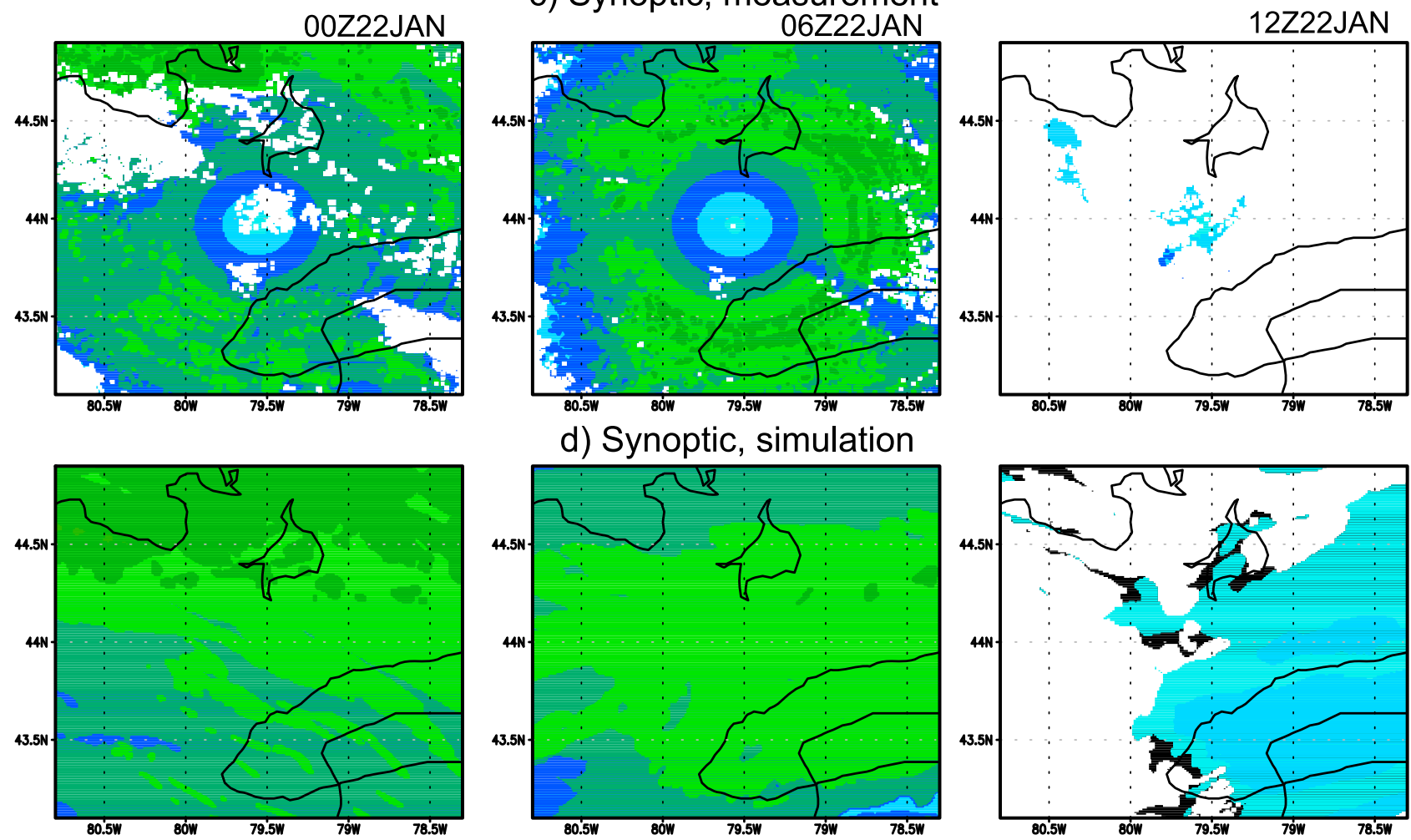

d) Synoptic, simulation

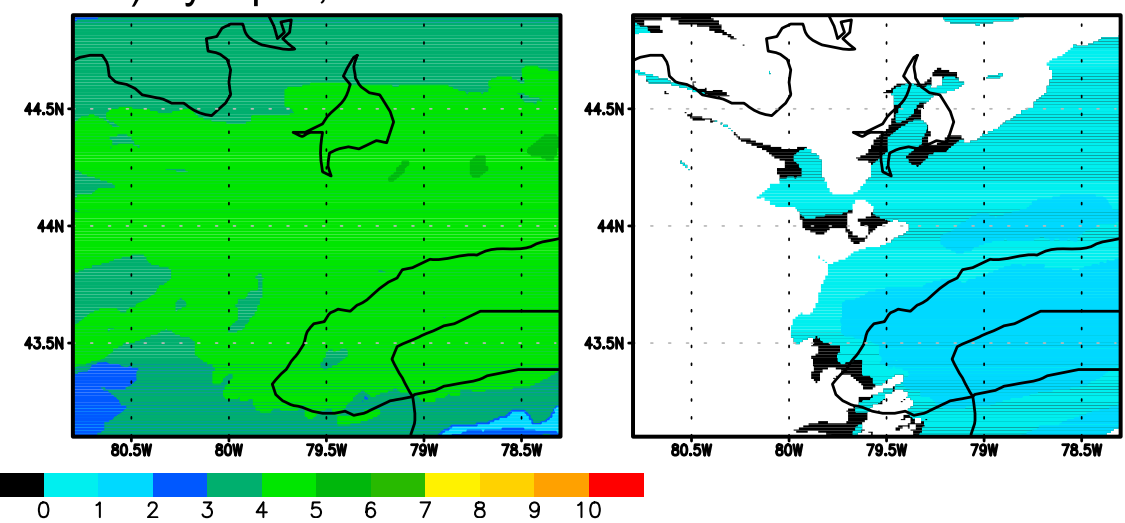

Figure 3. Same as Figure 2 but for $0 \mathrm{~dB}$ echo-top height (km). 
a) Lake-effect, measurement

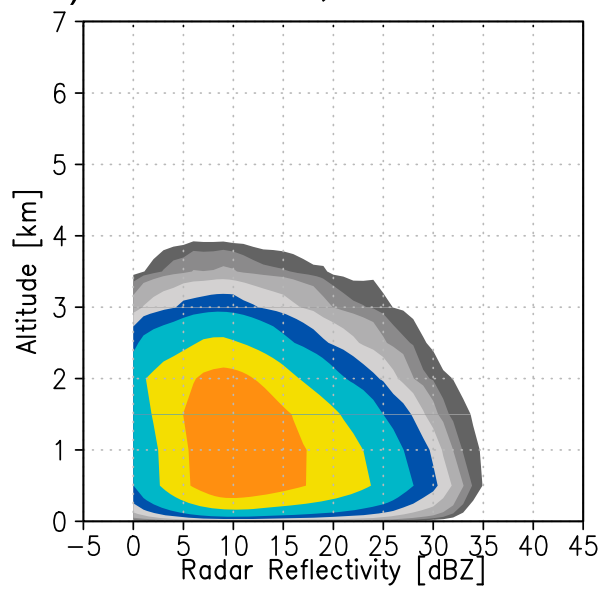

c) Synoptic, measurement

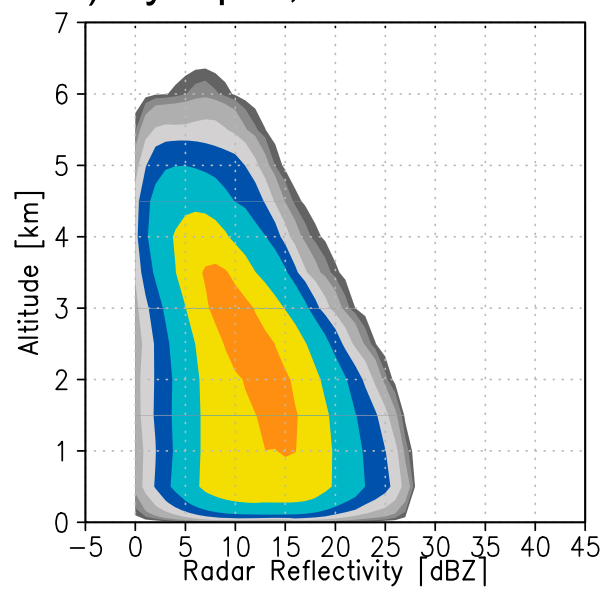

b) Lake-effect, simulation

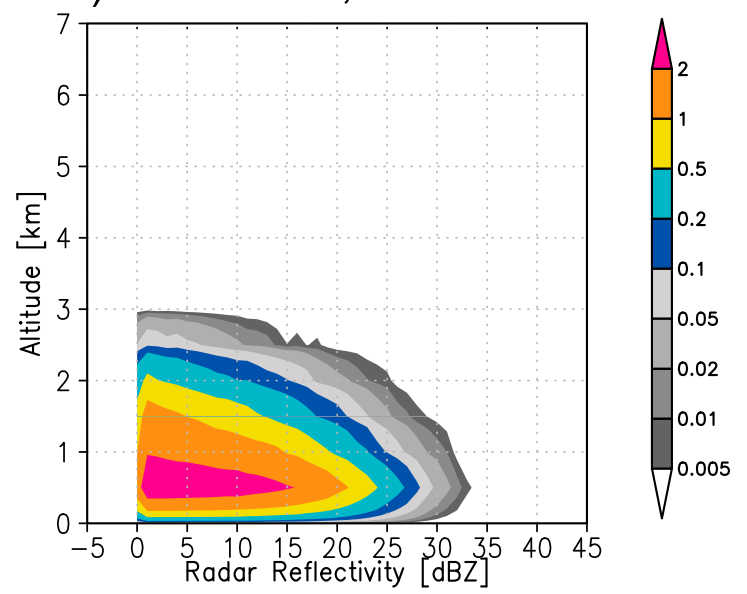

d) Synoptic, simulation
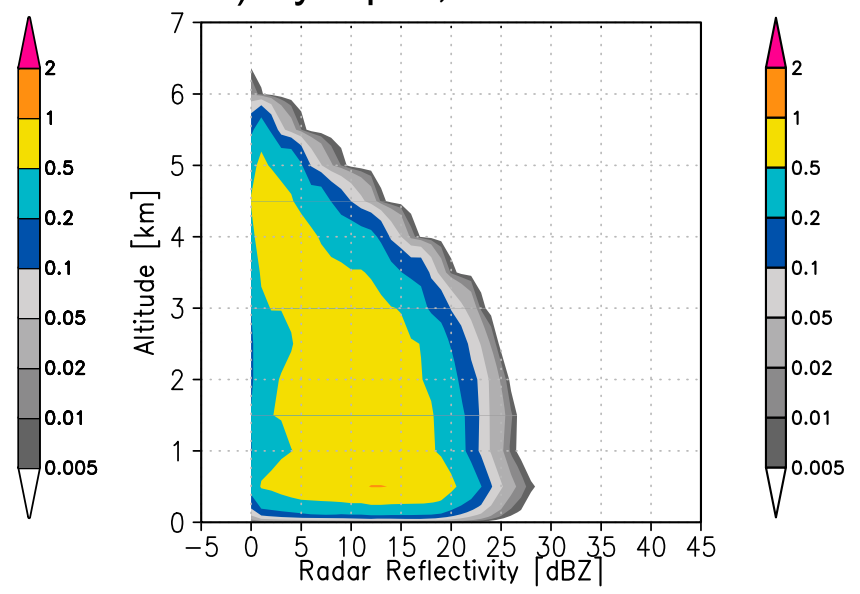

Figure 4. Normalized contoured frequency with altitude and reflectivity diagram derived from (a, c) King City radar measurement and (b, d) WRF-SBM simulation.

(synoptic case), respectively, by the double-fenced international reference (DFIR) gauge at the CARE site [Huang et al., 2010]. The corresponding values in the WRF-SBM simulations are $3.39 \mathrm{~mm}$ for the lake-effect event and $2.16 \mathrm{~mm}$ for the synoptic event. This significant underprediction of surface precipitation rate in the lake-effect case is considered to be mostly due to a forecast error of the location of intense snowband. The simulated intense snowfall region is biased toward the western side, where the Blue Mountains are located. In contrast, the observed snowband occurred over the CARE site; 06Z snapshots of Figures 2a and $2 \mathrm{~b}$ illustrate the difference in observed and simulated snowband location. The maximum value in the simulated snowband region is more than $15 \mathrm{~mm}$ (Figure 9a), which is in good agreement with the surface precipitation amount observed at the CARE site.

\subsection{Analysis of the Microphysical Structures Using In Situ Observational Data}

[30] In this subsection, in situ aircraft and ground-based measurements are focused and compared with the simulated results in order to investigate the microphysical structures of the two snowfall systems.

\subsubsection{Aircraft Measurement}

[31] The NRC Convair 580 aircraft, equipped with a series of in situ and remote sensor, was employed to conduct the flight mission along CloudSat orbit between Ottawa and the CARE site during the measurement campaign. The two flight legs during 19-23 January 2007 fell predominantly within a domain with a radius of $\pm 0.5^{\circ}$ latitude and longitude centered at $79.5^{\circ} \mathrm{W}, 49.5^{\circ} \mathrm{N}$. The first and second flights continued approximately from $22 \mathrm{Z}$ on 19 to $02 \mathrm{Z}$ on 20 January (the lake-effect case) and from $00 \mathrm{Z}$ to $06 \mathrm{Z}$ on 22 January (the synoptic case), respectively. Data sampled by the instruments was recorded every $5 \mathrm{~s}$.

[32] Cloud particle size distribution was measured by the Particle Measurement System's (PMS) two-dimensional cloud (2D-C) and two-dimensional precipitation (2D-P) imaging probes. Sampled particles were divided into 33 size bins with midpoint diameters ranging from $30 \mu \mathrm{m}$ to $2.5 \mathrm{~cm}$ (A. J. Heymsfield et al., Ice cloud particle size distributions and pressure-dependent terminal velocities from in situ observations at temperatures from 0 to $-86^{\circ} \mathrm{C}$, submitted to Journal of the Atmospheric Sciences, 2012). Note that the sampling does not separate particles into particular hydrometeor categories. Concentrations in bins below $100 \mu \mathrm{m}$ are 
not reliable and are not used to estimate the ice water content from the particle size distributions. Total condensate water content (TWC) was measured by the DMT cloud probe and counterflow virtual impactor (CSI). The CSI probe has approximately $11 \%$ uncertainty for TWC of $0.2 \mathrm{~g} / \mathrm{m}^{3}$ and larger uncertainty for smaller TWC, when operating in its normal configuration [Twohy et al., 1997]. It cannot be reliably detect TWC below $0.01 \mathrm{~g} / \mathrm{m}^{3}$; however, the CSI probe has a shorter region for condensate evaporation which adds to the uncertainty in a yet uncharacterized way.

[33] The bulk effective particle radius (PMS $r_{e}$ ) is defined for the PMS 33 bins as the following form:

$$
\text { PMS } r_{e}=\frac{\sum_{i=3}^{33} r_{i}{ }^{3} N_{i}}{\sum_{i=3}^{33} r_{i}{ }^{2} N_{i}},
$$

where $r_{i}$ is a half of the maximum diameter of $i_{t h}$ bins and $N_{i}$ is the particle number concentrations. By combining CSI measurements, the bulk effective particle density (CSI-PMS $\rho_{e}$ ) is formulated in the following form [Heymsfield et al., 2004] using TWC estimated by the CSI and particle volume concentration assuming that all PMS particles are spherical:

$$
\text { CSI - PMS } \rho_{e}=\frac{\text { TWC }_{C S I}}{\sum_{i=3}^{33} \frac{4}{3} \pi r_{i}{ }^{3} N_{i}} .
$$

[34] These parameters correspond to representatives of particle size and density measured by the airborne instruments. No liquid water is included in the calculation of these parameters. Note that CSI underestimates the water content calculated by PMS 2D PSD by at most order of $50 \%$, so that there is corresponding possibility of underestimation of CSI-PMS $\rho_{e}$.

[35] The corresponding PMS $r_{e}$ and CSI-PMS $\rho_{e}$ are calculated from output of the WRF-SBM simulation on the basis of the following approach for comparison with the aircraft measurement: The simulation output including hydrometeors PSDs is recorded per hour (model time). At grid points in the output, each 43 binned PSD of the 6 ice hydrometeor categories is distributed over the 33 bins identical to the binned size ranges of the aircraft PMS program, and then one 33 binned PSD is recomposed by totaling. This is an imitation of the actual PMS sampling to clouds. Note that the two-dimensional video disdrometer (2DVD) correlation is used to take into account realistic irregular shapes of snow aggregates in the distribution calculation; detail of the correction is summarized in Appendix A. The mass-size relationships assumed in the SBM [e.g., Khain and Sednev, 1995] are used for the calculation of the other hydrometeor categories. Then, PMS $r_{e}$ (equation (2)) and the denominator of equation (3) can be calculated using the recomposed 33 binned PSD. TWC estimated by the CSI (the numerator of equation (3)) is assumed to be identical to the total mass concentration of 43 binned PSDs of the 6 ice hydrometeor categories and subsequently CSI-PMS $\rho_{e}$ can be calculated using equation (3). The two parameters are finally sampled from the model grid points only in the vicinity of the cross sections, during the aircraft sampling periods. The two flight legs of the lake-effect and synoptic cases are roughly approximated to be the cross sections of $\left(44.2^{\circ} \mathrm{N}, 80.0^{\circ} \mathrm{W}\right)-\left(44.8^{\circ} \mathrm{N}, 79.8^{\circ} \mathrm{W}\right)$ and $\left(43.9^{\circ} \mathrm{N}, 79.6^{\circ} \mathrm{W}\right)-$ $\left(44.6^{\circ} \mathrm{N}, 79.5^{\circ} \mathrm{W}\right)$, respectively. Although an effect of the instrument noise is not considered, this approach allows a proper comparison of microphysical structure between the simulation and measurement [Matsui et al., 2009].

[36] Figures 5a and 5c show scatter diagrams between PMS $r_{e}$ and CSI-PMS $\rho_{e}$ derived from the WRF-SBM simulations and the aircraft measurements. This plot indicates a bulk size-dependent spectrum of particle density. Observed $r_{e}-\rho_{e}$ relationships (triangle marks) show that $\rho_{e}$ decreases with an increase in $r_{e}$, generally. This means that the maximum dimension to mass tends to be increased when ice crystals are involved in aggregation. A comparison between the observed relationships of the two cases shows that the synoptic case tends to have smaller density with less variability as a function of size. This result has led to the speculation that the microphysics structure of the synoptic case is dominated by the nonrimed elongated snow aggregates with relatively small density, while the lake-effect case tends to have rimed snow aggregates with large density.

[37] The corresponding plots of the simulation (square marks) show that $r_{e}-\rho_{e}$ relationships of the simulation and measurement have a common point that is distinct between the two cases. A group of relatively large density around $r_{e}$ of $700 \mu \mathrm{m}$ is simulated and observed in the lake-effect case, as compared with the plots of the synoptic case. This difference can be explained by density change through presence or absence of riming on snow aggregates by collision with supercooled droplets. In the lake-effect case, the microphysical structure of the intense snowstorm is characterized by presence of supercooled water and resultant increase in particle density through riming process. The simulated $r_{e}-\rho_{e}$ relationship is not a logarithmic line form in which $\rho_{e}$ decreases with an increase in $r_{e}$. The scatter of plots spreads out around $r_{e}$ of $550 \mu \mathrm{m}$ to $\rho_{e}$ of approximately $0.4 \mathrm{~g} / \mathrm{cm}^{3}$, which is equal to the bulk density of graupel assumed in the SBM (Figure 1a). This pattern seems to represent a transfer from nonrimed snow aggregates to graupel via rimed snow aggregates. This result is consistent with the fact that snow aggregates and graupel are dominant on the corresponding model grid points for the airborne comparison (Figure 6b). The mechanism characterizing the simulated $r_{e}-\rho_{e}$ relationship is consistent with the speculation that the observed clouds include rimed snow aggregates with a relatively large density, though the simulation cannot reproduce a part of large $r_{e}$ side over approximately $1000 \mu \mathrm{m}$. Figure 6b also makes sure of the presence of supercooled water that can be a source of riming by collision with snow aggregates in the simulation. All liquid droplets are supercooled because atmospheric temperature is less than $0^{\circ} \mathrm{C}$ in all layers in this case. The microphysical structure with supercooled water and resultant riming can be implicated in the general weather condition by the following: The relatively cold and strong wind on the lake surface [Shi et al., 2010, Figure 2] causes a large upward moisture flux from the lake; the value of upward moisture flux is approximately twice as much as in the synoptic case on average. Saturation with respect to both water and ice is accomplished in the boundary layer clouds of low saturation pressure because of the low air temperature. 


\section{a) Lake-effect, airborne}

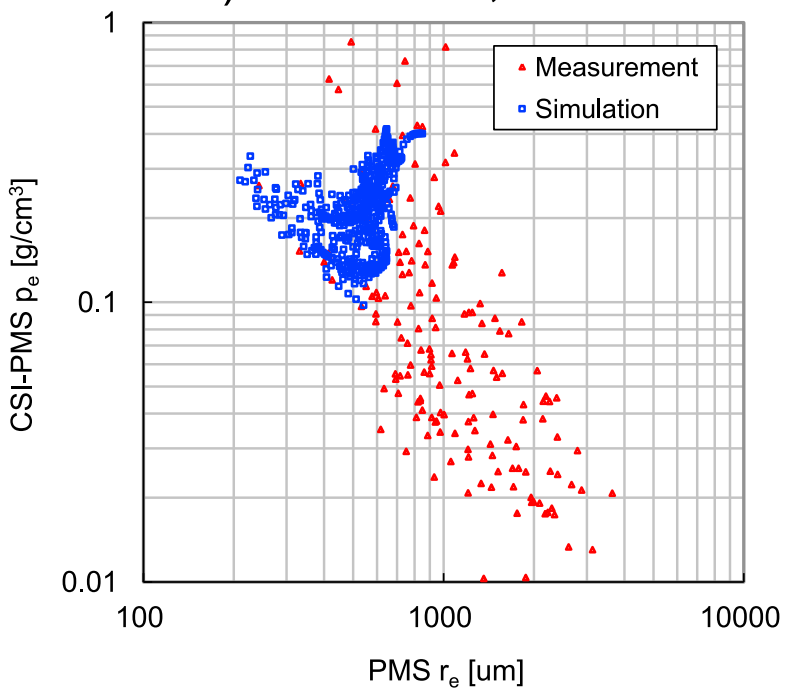

c) Synoptic, airborne

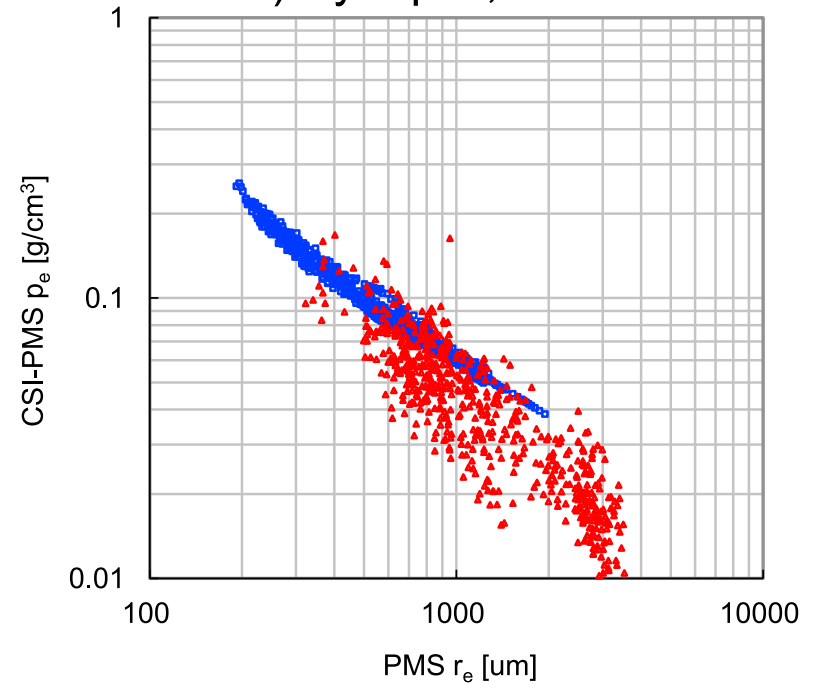

b) Lake-effect, ground

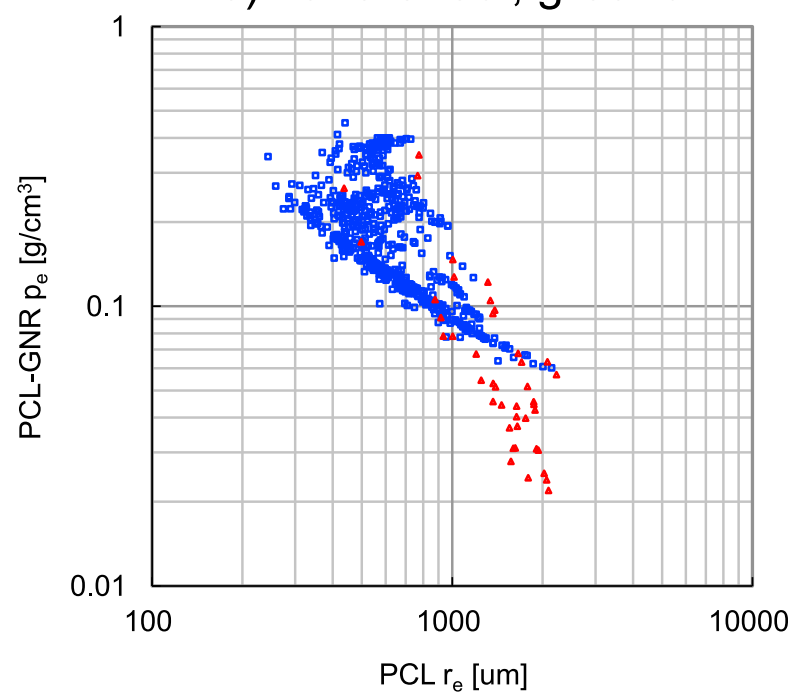

d) Synoptic, ground

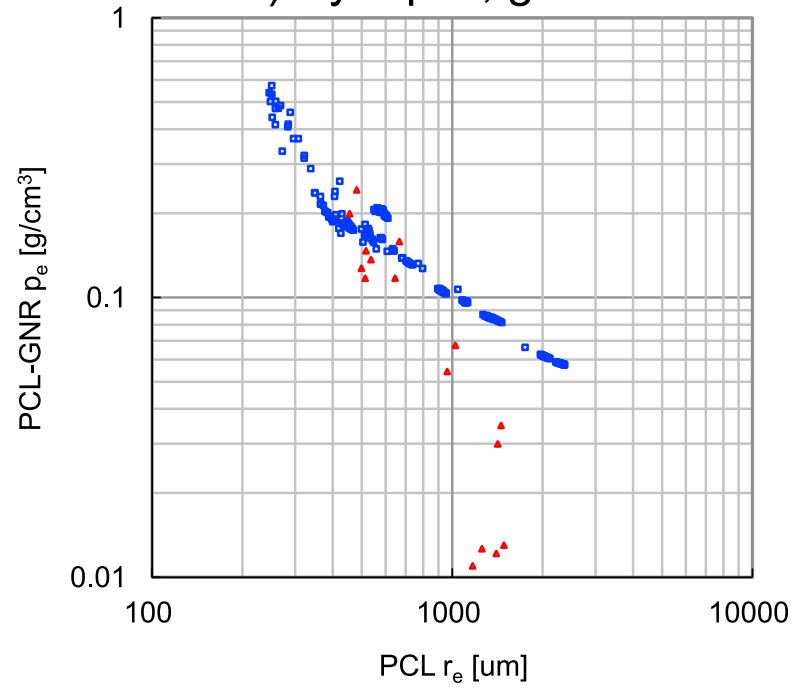

Figure 5. Scatter diagrams $(\mathrm{a}, \mathrm{c})$ between airborne instrument-based bulk density and bulk effective radius sampled for the water contents larger than $0.1 \mathrm{~g} / \mathrm{m}^{3}$ and $(\mathrm{b}, \mathrm{d})$ between ground instrument-based bulk density and bulk effective radius. Triangle and square marks denote the values derived from the measurement and the simulation, respectively.

[38] In contrast, the calm snowfall in the synoptic case is characterized by nonrimed snow aggregates and absence of supercooled water. The simulated $r_{e}-\rho_{e}$ relationship is logarithmically linear and $\rho_{e}$ uniquely decreases with an increase in $r_{e}$, following the corresponding relationship of nonrimed snow aggregates assumed in the SBM (Figure 1a). This result is consistent with the fact that snow aggregates are significantly dominant on the sampled grid points (Figure 6d). Rimed snow aggregates and graupel with large particle densities are not generated in this case, because there is no supercooled water. The simulated pattern of the $r_{e}-\rho_{e}$ plots is overall agreement with the observed one with exception of slight underestimation of $r_{e}$. The feature of the simulated result does not contradict the speculation that the observed clouds are occupied by nonrimed snow. In the synoptic case, only ice saturation is accomplished in the simulated clouds. Moisture supply from the lake has an insignificant effect on the snowfall system, because small moisture supply by the weak surface wind hardly reach the synoptic system clouds aloft.

[39] Furthermore, the simulated presence or absence of supercooled water can be directly verified in the same aircraft measurements. Presence of supercooled droplets is estimated using voltage signal measured by the Rosemount Icing (RICE) probe [Heymsfield and Miloshevich, 1989]. The RICE measurement shows that the anomalous voltage signals larger than $2.2 \mathrm{~V}$ were observed in the lake-effect cases around the altitude ranging from $1 \mathrm{~km}$ to $3 \mathrm{~km}$, which indicates presence of supercooled droplets (Figure 6a). This 
a) Lake-effect, aircraft measurement RICE for supercooled liquid water

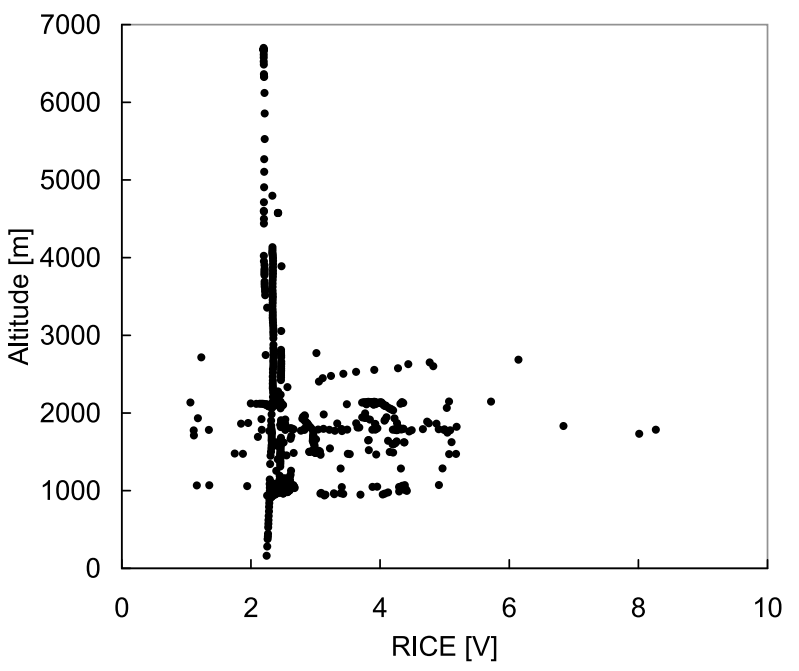

c) Synoptic, aircraft measurement RICE for supercooled liquid water

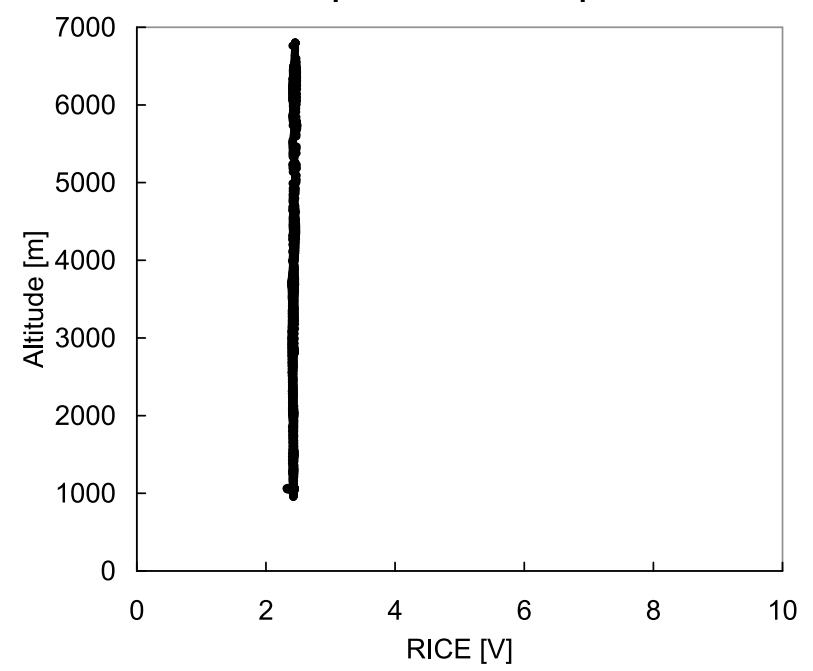

b) Lake-effect, WRF-SBM simulation hydrometeor class distribution

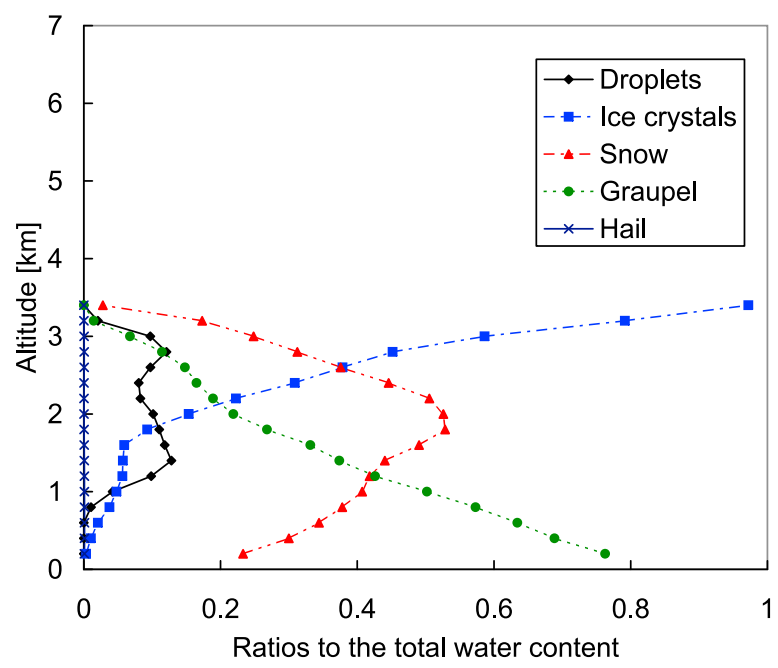

d) Synoptic, WRF-SBM simulation hydrometeor class distribution

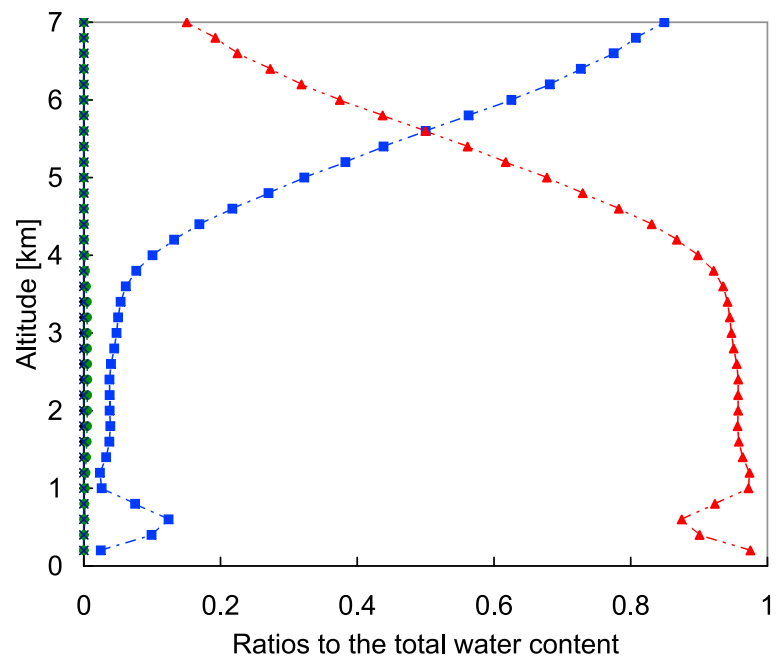

Figure 6. (a, c) Vertical distribution of Rosemount Icing (RICE) probe voltage signals sampled by aircraft measurements. (b, d) Vertical distribution of the dominant hydrometeor types in the WRF-SBM simulation for the corresponding grid points of the airborne sampling.

result justifies the presence of supercooled water in the simulation of the lake-effect case (Figure 6b). In contrast, there are no abnormal RICE signals for supercooled water in the synoptic case (Figure 6c), so that the absence of supercooled water in the simulation of the case is also justified (Figure 6d).

[40] In addition, the aircraft measurements may provide a sign of graupel together with supercooled water. Figure 7 illustrates a correlation between RICE voltage signals and particle area ratio with a diameter of approximately $800 \mu \mathrm{m}$. A high value close to 1.0 of area ratio means that the particle has a spherical shape. Area ratios of high magnitudes involved in anomalous RICE signals in the lake-effect case demonstrate a transition from snow aggregates to spherical graupel as a result of riming. In contrast, the parameters of slightly lower magnitudes in the synoptic case can be interpreted as continuous existence of nonspherical snow aggregates without riming.

[41] The WRF-SBM simulation cannot reproduce observed low $\rho_{e}$ near $0.01 \mathrm{~g} / \mathrm{cm}^{3}$. This is due to the relationship between density and size of nonrimed snow aggregates assumed in the SBM (Figure 1a). Another highlighted difference between the simulation and measurement is underestimation of $r_{e}$ in the lake-effect case. This point is discussed with additional simulations in the next sub section 3.3. 
a) 20 Jan. C3VP (lake-effect case)

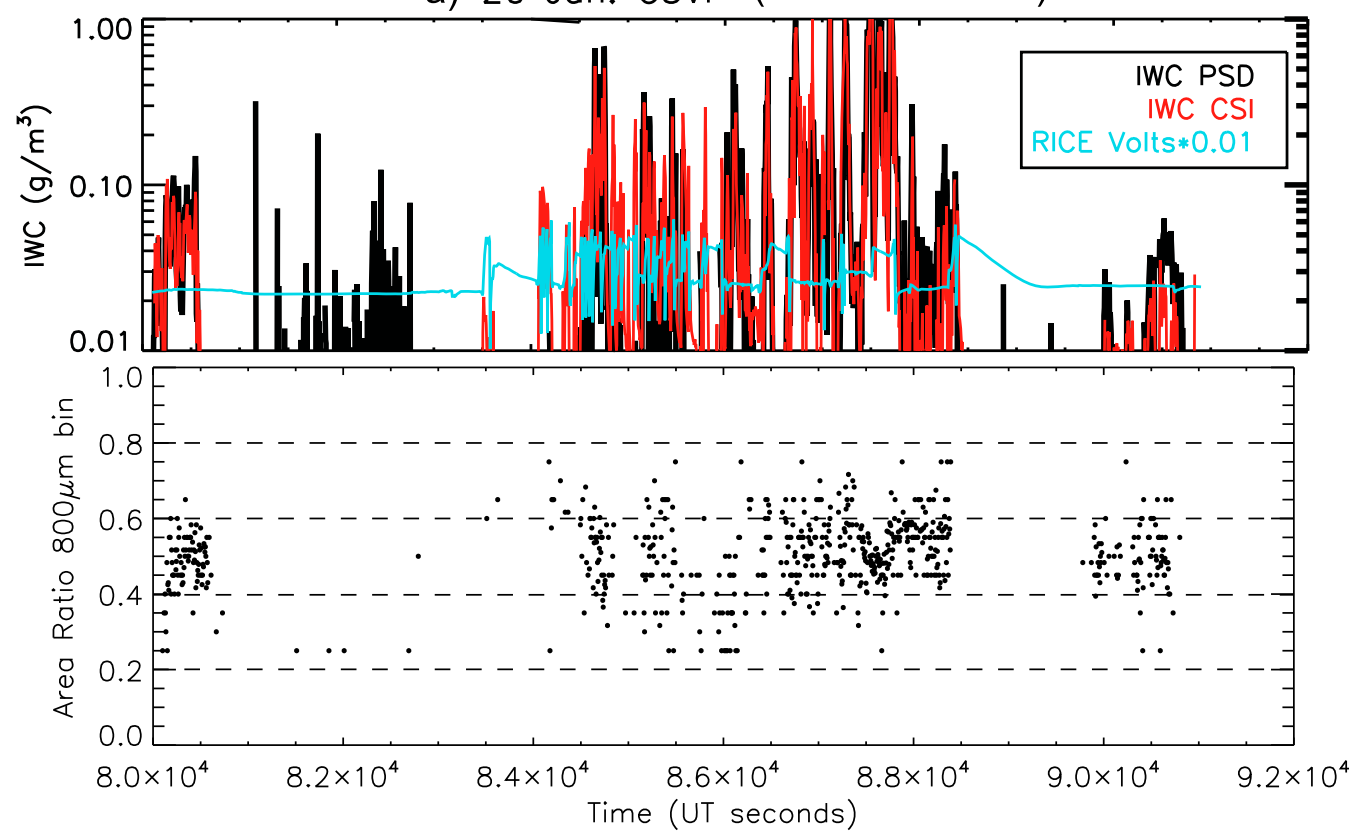

b) 22 Jan. C3VP (synoptic case)
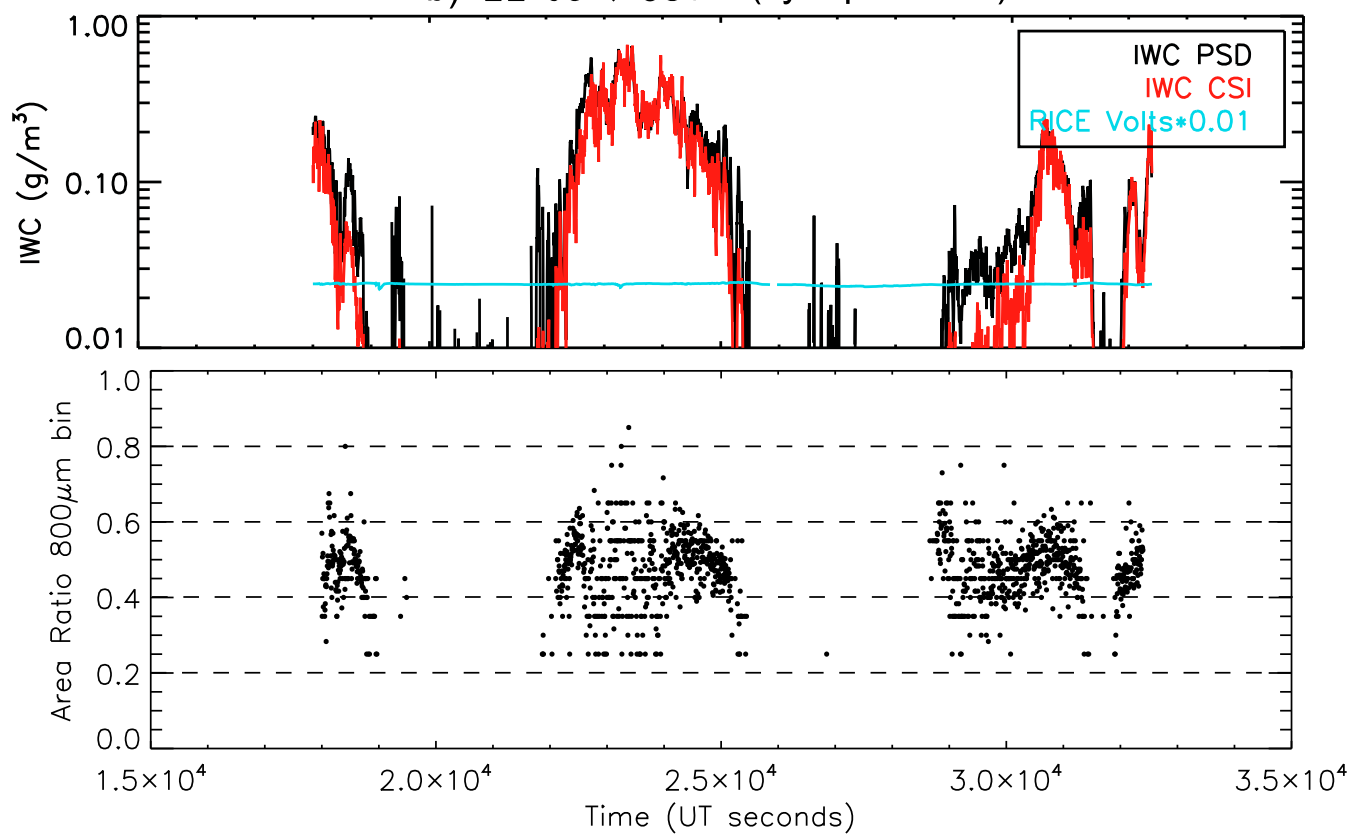

Figure 7. Time series of ice water contents (IWC) calculated from the Particle Measurement System's (PMS) two-dimensional cloud (2D-C) and two-dimensional precipitation (2D-P) imaging probes and counterflow virtual impactor (CSI), RICE voltage signal, and area ratio in the $800 \mu \mathrm{m}$ size bin of the PMS particle size distributions in the aircraft measurements (a) on 20 January (lake-effect case) and (b) on 22 January (synoptic case).

\subsubsection{Ground-Based Measurement}

[42] Three ground instruments, laser optical Particle Size and Velocity (Parsivel) disdrometer, Geonor weighing bucket gauge and 2DVD, were installed at the CARE site. The Parsivel disdrometer [Löffler-Mang and Joss, 2000] can measure the maximum length of the particle in a horizontal plane, and its raw output is the number of particles in 32 size and 32 fall velocity bins. The size range is between 0.3 to $25 \mathrm{~mm}$, while the falling velocity has a range of 0.05
$20.8 \mathrm{~m} \mathrm{~s}^{-1}$. The assumption of measured maximum length of the snow aggregate as a diameter results in errors in PSD and shape parameters as in the work of Battaglia et al. [2010]. The Geonor bucket gauge can measure precipitation rate in the form of liquid accumulation per averaging period, typically several minutes. The 2DVD disdrometer [Kruger and Krajewski, 2002] measures the maximum width and height of falling particle as well as the falling velocity by the two orthogonal cameras where the measuring planes 
have $6 \mathrm{~mm}$ apart. This 2DVD system provides the shape parameters of snow aggregates to calculate the apparent volume and diameter [Huang et al., 2010], which are used in Appendix A.

[43] Precipitation PSD is determined to be series of particle number concentrations as a function of the maximum particle length from the raw output of the Parsivel measurement. We produce a bulk size-dependent spectrum of particle density at the ground level, using the approach that is similar to the aircraft measurement analysis. The bulk effective particle radius for the Parsivel measurement (PCL $\left.r_{e}\right)$ is defined following the equation that is similar to equation (2):

$$
\text { PCL } r_{e}=\frac{\sum_{j=1}^{32} r_{j}{ }^{3} N_{j}}{\sum_{j=1}^{32} r_{j}{ }^{2} N_{j}},
$$

where $r_{j}$ is a half of the maximum length in a horizontal optical plane of $j_{t h}$ bin and $N_{j}$ is the particle number concentration of $j_{t h}$ bin.

[44] Solid-phase accumulation volume rate estimated from the Parsivel measurement $\left(\mathrm{P}_{\mathrm{PCL}}\right)$ is combined to the measurement data of (melted) liquid-phase accumulation mass rate $\left(\mathrm{P}_{\mathrm{GNR}}\right)$ by the Geonor bucket gauge. If it is assumed that both Parsivel and Geonor gauge sampled the same accumulation object, the ratio of the two variables corresponds to bulk density (mass per unit volume) of the accumulation. The similar approach using 2DVD disdrometer and Geonor gauge was employed to determine the relationship between density and diameter in the Colorado snowstorm [Brandes et al., 2007]. The bulk density of surface accumulation, GNR-PCL $\rho_{e}$, is defined as the ratio of these accumulation rates:

$$
\mathrm{GNR}-\mathrm{PCL} \rho_{e}=\frac{P_{G N R}}{P_{P C L}} .
$$

These two parameters correspond to representatives of bulk particle size and density measured by the ground-based instruments.

[45] The corresponding PCL $r_{e}$ and GNR-PCL $\rho_{e}$ are calculated from the simulation output using the approaches that are similar to those in the aircraft comparison: For all surface grids of the output, surface fluxes of 43 binned PSDs are calculated using the spatial distributions of PSDs and the terminal fall velocities. Then, each 43 binned PSD is distributed over the 32 bins identical to the binned size ranges of the Parsivel measurement program, and subsequently one 32 binned PSD is recomposed by totaling. 2DVD correlation (Appendix A) is applied to the calculation of the distribution. Then, PCL $r_{e}$ is calculated following equation (4). On the other hand, GNR-PCL $\rho_{e}$ is obtained as the ratio of mass to volume computed from the 32 binned PSD. The two parameters are finally sampled for surface grid points within a domain of $4 \mathrm{~km}$ square centered at the CARE site for the comparison.

[46] Figures 5b and 5d show scatter diagrams of the ground-based observables (PCL $r_{e}$ and GNR-PCL $\rho_{e}$ ) for $24 \mathrm{~h}$ (20 and 22 January) from the ground-based measurements and the WRF-SBM simulations. Note that the number of observed samples (triangle marks) is very small because of the limited sampling on the particular spot, in addition to the low frequent measurement of the Geonor bucket gauge with waiting for melting of solid-phase precipitation; time integration of $15 \mathrm{~min}$ is employed to ensure a stable measurement by the bucket gauge in this study. Observed $r_{e}-\rho_{e}$ relationship shows that $\rho_{e}$ overall decreases with an increase in $r_{e}$, similarly to that in the aircraft measurement. The observed plots show smaller effective radii than those of the corresponding airborne plots generally, though relatively large particles should fall to the surface. The reason for these smaller radii is uncertain: probably because of the limited sampling, the difference in the definitions of bulk effective radii between ground-based and aircraft measurements, time integration of sampling, effect of sublimation under cloud base, or others. A comparison between the observed plots of the two cases suggests that the synoptic case tends to have slightly smaller density. This trend is in agreement with that of the airborne measurements; that is, the presence or absence of riming influences on the microphysical structures of surface precipitation also.

[47] The corresponding simulation results (Figures 5b and 5d) show a part of relatively large density from $r_{e}$ of $500 \mu \mathrm{m}$ to $1000 \mu \mathrm{m}$ in the lake-effect case, whereas there is a part of large density around $r_{e}$ of $300 \mu \mathrm{m}$ in the synoptic case. The part of high density in the lake-effect case corresponds to rimed snow aggregates and the derivative graupel. The pattern of the simulated plots is similar to the simulated one in the airborne analysis (Figure 5a), except for the large size part of $r_{e}$ over $1000 \mu \mathrm{m}$. The population of the simulated plots covers with the observed plots, with the exception of the small $\rho_{e}$ part. A poor assumption of the relationship between density and size of nonrimed snow aggregates in model microphysics causes the discrepancy at observed low density near $0.01 \mathrm{~g} / \mathrm{cm}^{3}$, as similarly found in the comparison with the aircraft measurement in the synoptic case (Figure 5b).

[48] The ground-based simulated pattern in the synoptic case is largely different from those of both the ground-based observed one and the airborne simulated one in the same case. The part of large density around $r_{e}$ of $300 \mu \mathrm{m}$ is due to a contribution of ice crystals. Although snow aggregates are the dominant type of the precipitation, high relative humidity for ice over $100 \%$ and the resultant ice crystals are partially simulated near the surface in the vicinity of the CARE site, especially after $12 \mathrm{Z}$ on the day; the $12 \mathrm{Z}$ plot of Figure $2 \mathrm{~d}$ provides a glimpse of the situation. This is considered to be mostly due to some forecast errors rather than the problem of microphysics.

\subsection{Additional Simulations With Different PBL Options or No Riming Process in the Lake-Effect Case}

[49] The purpose of conducting addition simulations in the lake-effect case is to highlight how PBL process affects riming process and associated formation of the microphysical structure of the snowstorm. In addition, we sought to identify a source of the discrepancy between the measurements and simulation. The specifications of the control and addition simulations are summarized in Table 1. (1) MellarYamada-Janjic Level 2.5 turbulent closure model (MYJ) is 
Table 1. List of the Default and Additional Simulations for the Lake-Effect Case

\begin{tabular}{|c|c|}
\hline Abbreviation & Specifications \\
\hline MYJ (default) & $\begin{array}{c}\text { Mellar-Yamada-Janjic Level } 2.5 \\
\text { turbulent closure }\end{array}$ \\
\hline $\mathrm{MYJ}+\mathrm{Nr}$ & MYJ (No riming $\left.{ }^{\mathrm{a}}\right)$ \\
\hline YSU & Yonsei University $\mathrm{PBL}^{\mathrm{b}}[$ Hong et al., 2006] \\
\hline MRF & $\begin{array}{l}\text { Medium Range Forecast PBL } \\
\text { model [Hong and Pan, 1996] }\end{array}$ \\
\hline
\end{tabular}

${ }^{\mathrm{a}}$ The riming process is turned off by making riming fraction always zero. ${ }^{\mathrm{b}} \mathrm{PBL}$, planetary boundary layer.

used in the run as default. (2) The MYJ PBL model is used but the rimed mass of snow aggregates is set always zero, so that riming process is turned off and all snow aggregates are nonrimed (MYJ + Nr). (3) Yonsei University PBL model (YSU) [Hong et al., 2006]. (4) The Medium Range Forecast PBL model (MRF) [Hong and Pan, 1996].
[50] First, we focus on the difference in the MYJ and $\mathrm{MYJ}+\mathrm{Nr}$ simulations in order to analyze the effect of riming process to the characteristics of the lake-effect snowstorm. Turn-off of the riming process has largely changed the pattern of correlation between particle density and size (Figure 8a). The $r_{e}-\rho_{e}$ relationship in the MYJ $+\mathrm{Nr}$ simulation is roughly logarithmic-linear, and $\rho_{e}$ uniquely decreases with an increase in $r_{e}$. This pattern is very close to that of nonrimed snow aggregates assumed in the SBM (Figure 1a) and simulated in the synoptic case (Figure $5 \mathrm{c}$ ). The part of large density close to $\rho_{e}$ of $0.4 \mathrm{~g} / \mathrm{cm}^{3}$ has been lost because of absence of rimed snow aggregates and graupel; this has led to disagreement with the corresponding part of the observed scatterplot. However, $r_{e}$ in the $\mathrm{MYJ}+\mathrm{Nr}$ simulation is increased up to excess over the maximum value of the observed plots, as compared with the result of the MYJ simulation. This increase in particle size is considered as being due to replacement of graupels by nonrimed snow aggregates with smaller density for the same

Lake-effect, airborne-based composites

a) MYJ(Blue) and MYJ+Nr(Green)

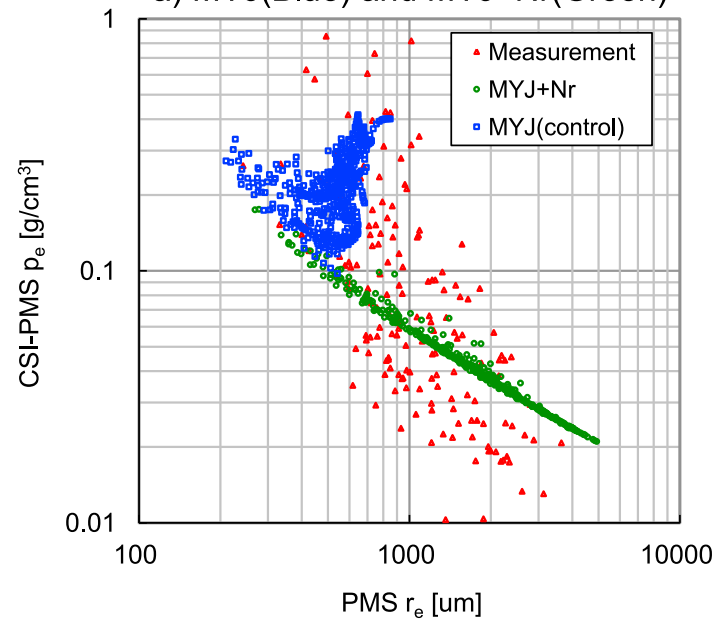

c) MRF

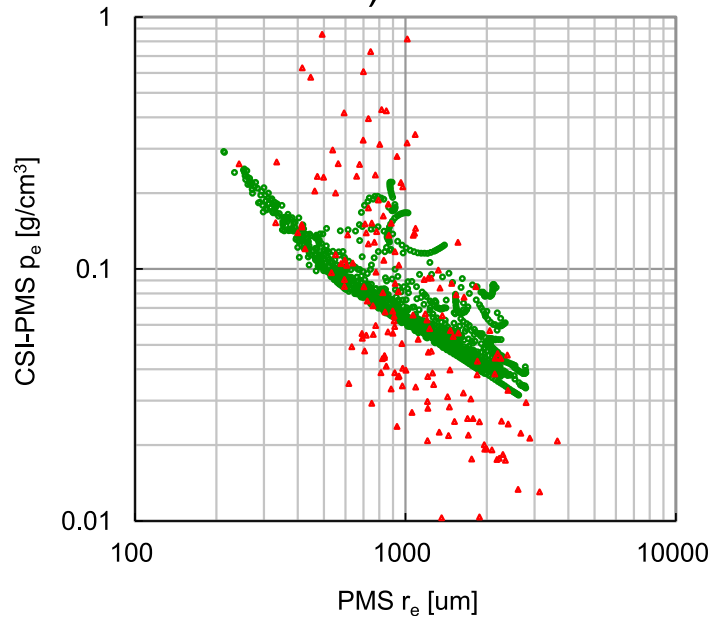

b) YSU

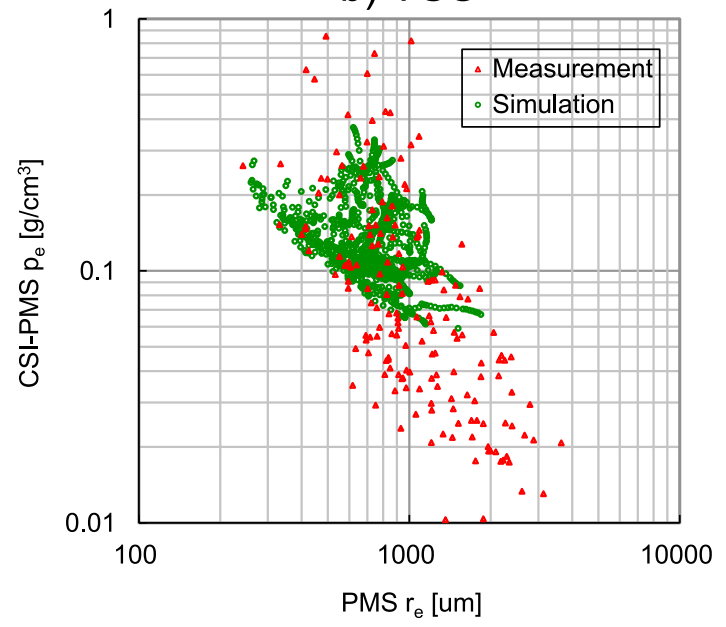

Figure 8. Same as in the airborne instrument-based diagrams of Figure 5 but for the additional simulations described in Table 1. Circle marks denote the values derived from the additional simulations. 


\section{4-hours-accumulated surface precipitation (20JAN, Lake-effect case)}

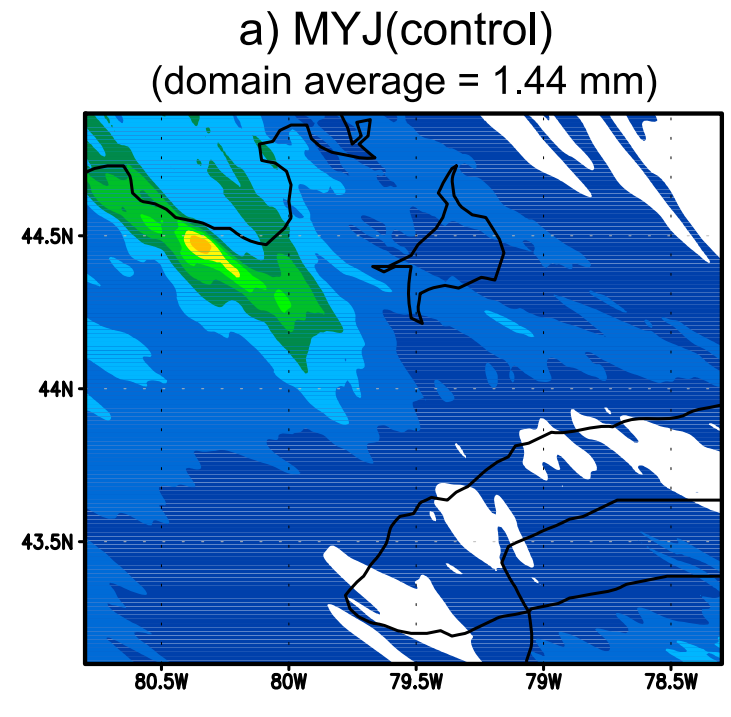

c) YSU

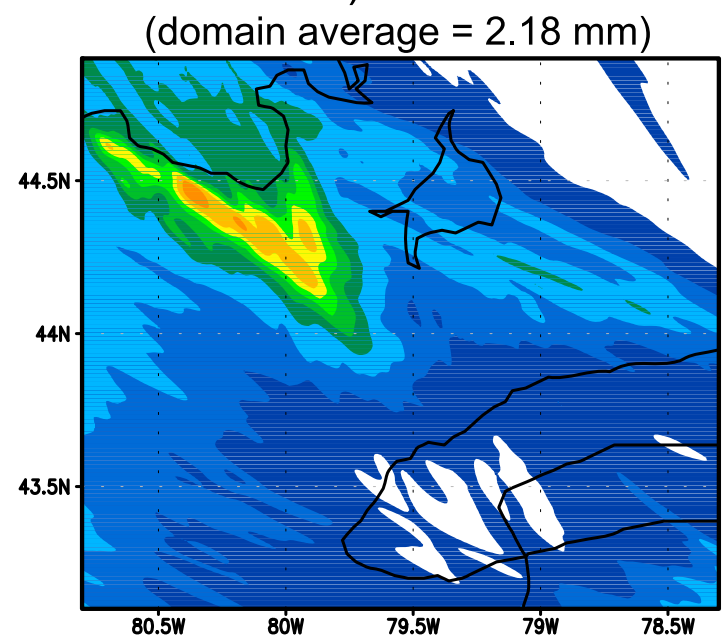

b) $\mathrm{MYJ}+\mathrm{Nr}$

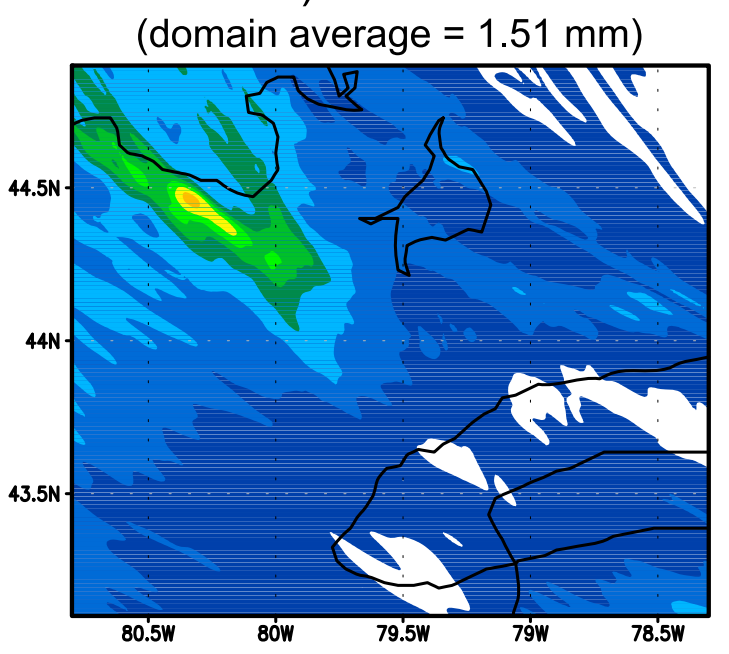

d) MRF

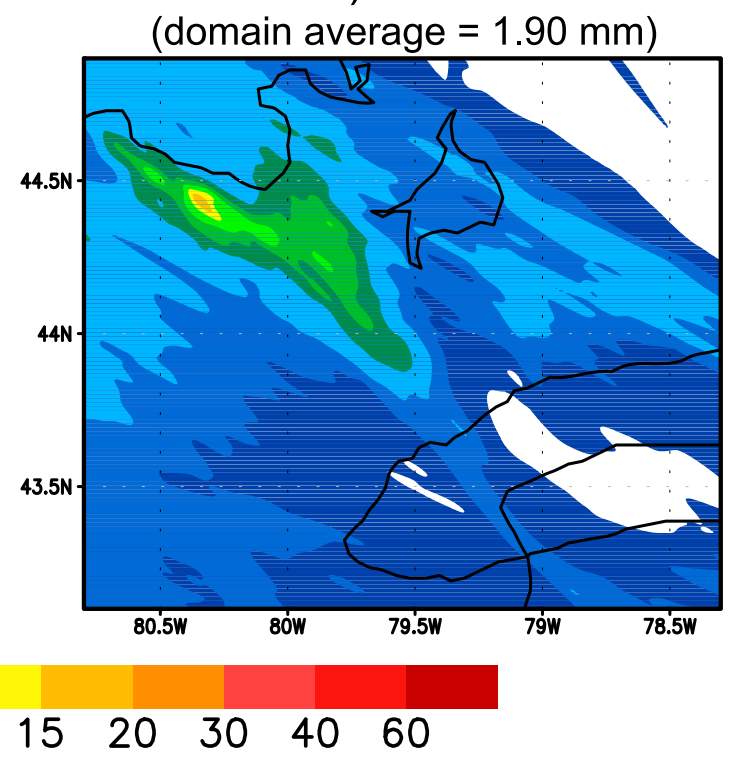

Figure 9. Horizontal distributions of $24 \mathrm{~h}$ accumulated surface precipitation from 00:00 UTC 20 January to 00:00 UTC 21 January calculated for WRF-SBM (a) Mellar-Yamada-Janjic Level 2.5 turbulent closure model (MYJ), (b) MYJ + Nr (no rimming: the riming process is turned off by making riming fraction always zero), (c) Yonsei University PBL model (YSU), and (d) Medium Range Forecast PBL model (MRF) simulations.

particle mass. In addition, the minimum value of the simulated $\rho_{e}$ approximates to the observed value near $0.01 \mathrm{~g} / \mathrm{cm}^{3}$. This result suggests that the microphysics in the MYJ simulation is biased toward overdominance of rimed snow aggregates and graupel. Presence of all three types, graupel and nonrimed and rimed snow aggregates, is thus necessary to represent the widely distributed scatter pattern of $r_{e}-\rho_{e}$ relationship observed by the aircraft measurement (Figure $8 \mathrm{a}$ ). Graupel contributes the part of the observed pattern with small $r_{e}$ and large $\rho_{e}$; nonrimed snow aggregates contribute the part of the pattern with large $r_{e}$ and small $\rho_{e}$, and rimed snow aggregates are regarded as the intermediate.

[51] The distributions of surface precipitation in the MYJ and MYJ + Nr simulations are quite similar (Figures 9a and $9 \mathrm{~b}$ ), though the airborne $r_{e}-\rho_{e}$ relationship has shown a remarkable change; the domain-averaged values of the MYJ and MYJ + Nr simulations are 1.44 and $1.51 \mathrm{~mm}$ in the form of the $24 \mathrm{~h}$ accumulation, respectively. This result suggests that the changes in particle size and density between the MYJ and MYJ + Nr simulations has little influence on 


\section{Lake-effect, WRF-SBM hydrometeor class distribution}
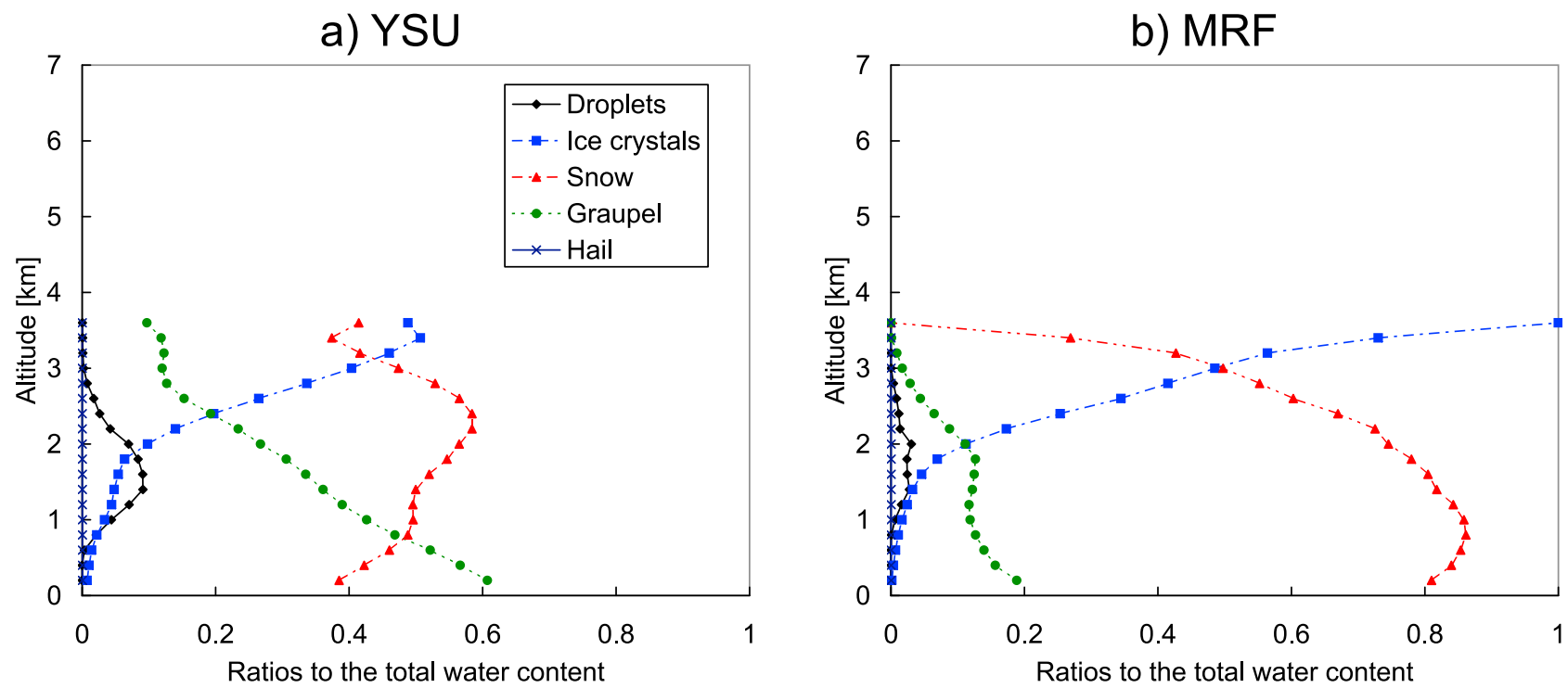

Figure 10. Same as Figures $6 \mathrm{~b}$ and $6 \mathrm{~d}$ but for the additional simulations described in Table 1 .

determining the transport of hydrometeors to the surface through sedimentation in this case. The little change in the surface precipitation patterns is due to the small height of the simulated snowstorm system and small falling velocities of hydrometeor particles. The maximum $r_{e}$ of graupel and rimed snow in the MYJ run is approximately $700 \mu \mathrm{m}$ (Figure 8a), and the maximum bulk falling velocity of graupel is estimated to be approximately $2 \mathrm{~m} / \mathrm{s}$ (Figure $1 \mathrm{~b}$ ). In contrast, the corresponding maximum falling velocity of nonrimed aggregates in the MYJ $+\mathrm{Nr}$ run is estimated to be approximately $1 \mathrm{~m} / \mathrm{s}$. The maximum difference in horizontally transported distances is estimated to be approximately $30 \mathrm{~km}$ for descending from $2 \mathrm{~km}$ height in the horizontal wind with the magnitude of $15 \mathrm{~m} / \mathrm{s}$. The actual difference is likely smaller than the estimated maximum, because the surface precipitation is concentrated at the location of the Blue Mountains with the relatively large terrain height.

[52] Second, we comparatively examined the simulation results using different PBL models (MYJ, YSU and MRF). The $r_{e}$ of the YSU and MRF simulations are overall increased from the MYJ simulation (Figure 8). As a result, the patterns of scatterplots of the YSU and MRF simulations correspond to be intermediate between those of the MYJ and MYJ $+\mathrm{Nr}$ simulations. The underestimation of $r_{e}$ in the MYJ run is reduced in YSU and especially in MRF run. The pattern of $r_{e}-\rho_{e}$ relationship in the YSU run is more scattered and closer to that of the observation, whereas the pattern of the MRF run is narrowly distributed and more similar to that of the MYJ $+\mathrm{Nr}$ run. These $r_{e}-\rho_{e}$ relationships are linked to the dominant hydrometer types (Figure 10), as shown in the comparative analysis between the lake-effect and synoptic cases (Figure 6). The MYJ simulation (Figure 6b) has the largest ratios of graupel and liquid droplets among the three simulations, whereas the MRF simulation (Figure 10b) has the smallest ones. The ratio of graupel is obviously positively correlated with that of liquid droplets, that is, supercooled water.
[53] The MYJ, YSU and MRF simulations have clearly distinct patterns of surface precipitation (Figure 9), as compared with little difference between the MYJ and MYJ $+\mathrm{Nr}$ simulations. The domain-averaged values of the YSU and MRF simulations are 2.18 and $1.90 \mathrm{~mm}$ in the form of the $24 \mathrm{~h}$ accumulation, respectively. The YSU and MRF simulations predict larger amount of surface precipitation, which are probably due to the large moisture supply from the lake and the difference in the PBL structures (Figure 11). In the MRF simulation (Figure 9d), the area of surface precipitation over $5 \mathrm{~mm}$ is extended from the lake Huron to the southeast on the downwind side. In addition, the area over $1 \mathrm{~mm}$ hangs over the lake Ontario and extends to outside of the plotted domain. On the other hand, in the YSU simulation (Figure 9c), the area of large precipitation amount over $12.5 \mathrm{~mm}$ is much increased from the MYJ run. The simulated value at the CARE site is approximated to the observed value of $12.3 \mathrm{~mm}$, but the area-wide precipitation seems to be much overpredicted as compared with the estimation of the surface precipitation from the radar measurement [Shi et al., 2010, Figure 3a; Huang et al., 2010, Figure 9].

[54] The values of upward moisture flux on the lake Huron in the YSU and MRF simulations are increased by an average of several tens percentage points from the MYJ run (Figure 11). Figure 12 shows comparison of temperature, vapor and relative humidity profiles among the simulations with the different PBL options at a coastal point of the lake Huron. Low temperature and small vapor mixing ratio below the altitude of $1.5 \mathrm{~km}$ are simulated in the MYJ run, as compared with those in the YSU and MRF runs. The PBL layer in the MYJ run seems to be thinner, because the inversion layer of temperature is simulated at lower level than in YSU and MRF runs. These behaviors are considered to be due to the difference in upward heat and moisture flux on the lake and subsequently related to the difference in surface precipitation. However, high relative humidity close 


\section{Upward moisture flux at the surface $\left(x 10^{5} \mathrm{~kg} / \mathrm{m}^{2} / \mathrm{s}\right)$ (1200UTC20JAN, Lake-effect case)}

a) MYJ(control)

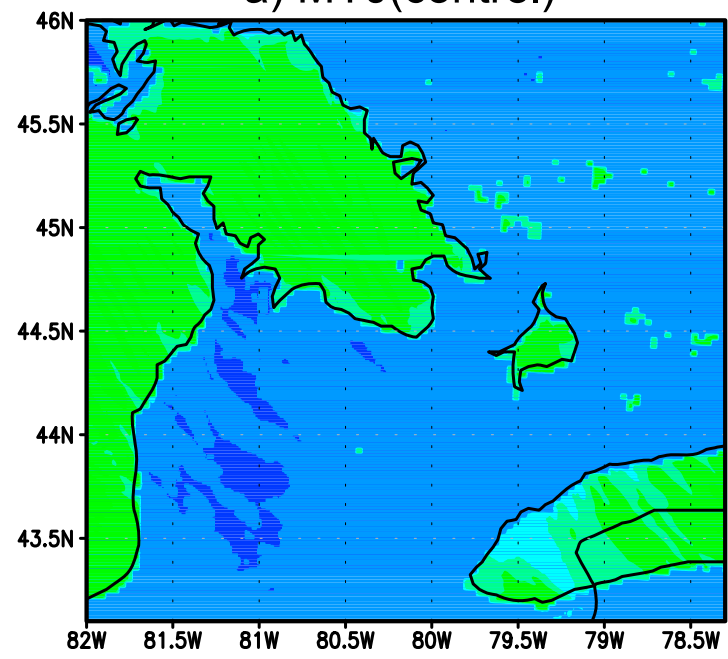

c) YSU

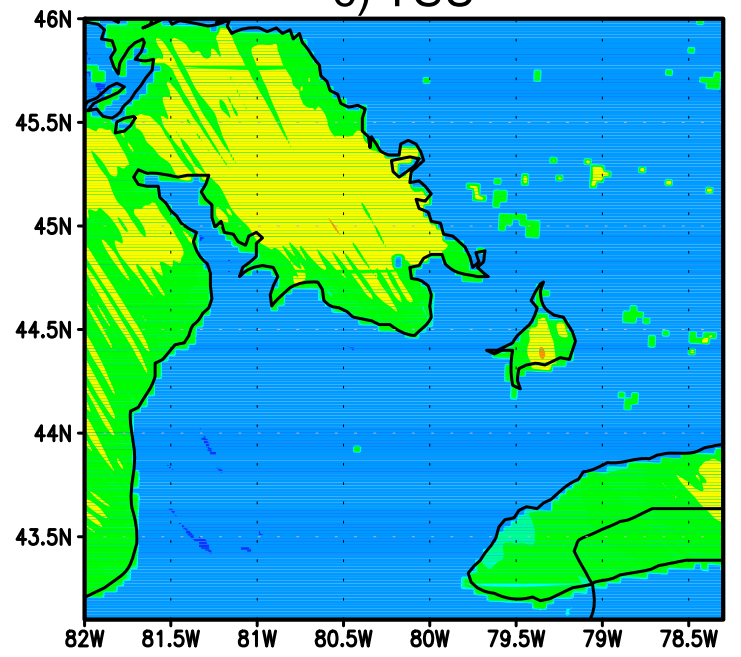

b) $\mathrm{MYJ}+\mathrm{Nr}$

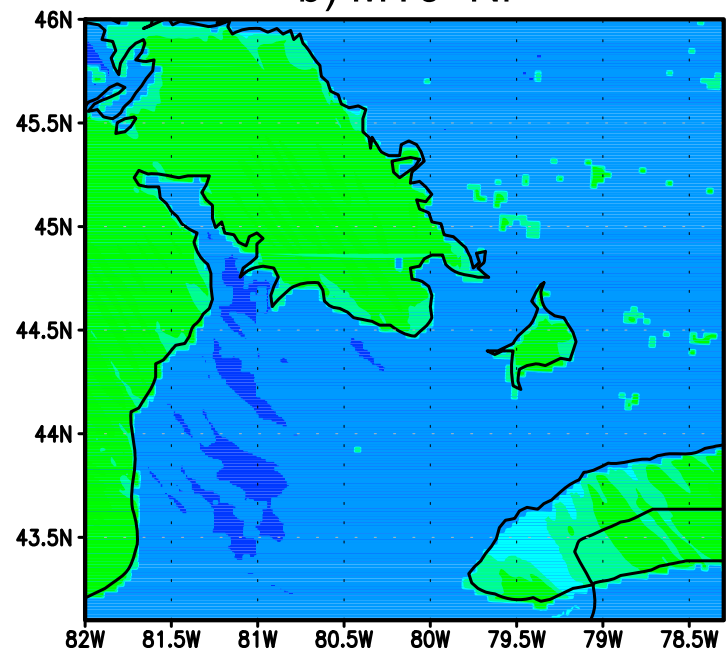

d) MRF

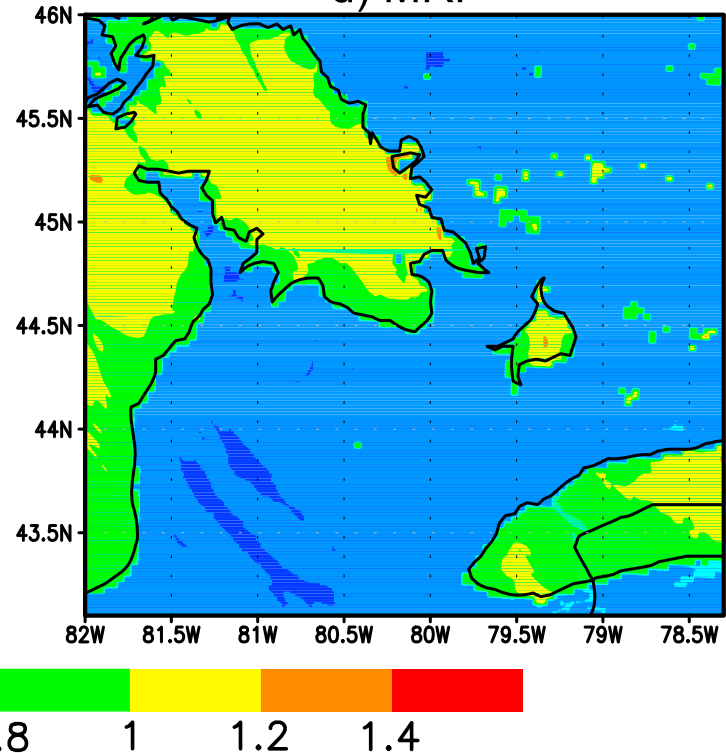

Figure 11. Horizontal distributions of upward moisture flux at the surface at 12:00 UTC 20 January simulated by the WRF-SBM (a) MYJ, (b) MYJ + Nr, (c) YSU, and (d) MRF runs.

to $100 \%$ is simulated even in the MYJ simulation despite smaller vapor mixing ratio, because of lower air temperature. Supercooled water is thus generated even in MYJ run in spite of the smaller moisture flux from the lake.

\section{Summary and Conclusions}

[55] In this study, the WRF-ARW 3.1.1 coupled with an updated spectral bin microphysics was employed for the case study upon cloud microphysical structures of two distinct snowfall events (lake-effect and synoptic) over the region near the Great Lakes. The updated microphysics scheme can predict rimed mass fraction on snow aggregates at every grid and time step, so that it can explicitly diagnose the bulk density of aggregates and allows a smooth transformation from snow aggregates to graupel. This implementation made it possible to simulate and study detailed ice microphysics, considering an influence of riming process. The simulation output was compared with the observed data by the C-band radar measurement, aircraft probe and impactor samplings, and ground-based particle counter and bucket gauge samplings. The off-line coupling to the G-SDSU allows a direct comparison between the simulation and measurement on the primary products base.

[56] Our results are summarized as follows:

[57] 1. The comparison with the C-band radar measurement showed that the simulation reproduced the distinct 
Vertical profiles of $\mathrm{T}, \mathrm{qv}, \mathrm{RH}$ (80W 44.5N, 1200UTC20JAN, Lake-effect case)


Figure 12. Comparisons of vertical profiles of (a) temperature (degree C), (b) water vapor mixing ratio $(\mathrm{g} / \mathrm{kg})$, and (c) relative humidity with respect to water $(\%)$ at $44.5^{\circ} \mathrm{N}$, $80^{\circ} \mathrm{W}$ at 12:00 UTC 20 January, obtained from the WRFSBM simulations with MYJ, YSU, and MRF PBL models.

basic structures of the two snowfall systems. The lake-effect event is characterized by containing localized low and intense snowstorm from the lake, whereas the synoptic event is characterized by widely distributed high-up and moderate snowfall.

[58] 2. The comparison with the airborne measurements showed that the distinct characteristic features of the microphysical structures in the two events were successfully simulated. The microphysics of the lake-effect snowstorm is characterized by rimed snow aggregates and graupel with relatively large bulk particle density, while the microphysics of the synoptic case snowfall is characterized by nonrimed snow aggregates with small particle density.

[59] 3. Supercooled droplets play a key role in forming the characteristic microphysical structure of the lake-effect case through riming process. The presence and absence of supercooled water in the simulations for both cases were justified by the same aircraft measurements.

[60] 4. Selection of PBL models has a remarkable impact on determining the cloud microphysical structure of the lake-effect snowstorm as well as the surface precipitation. In contrast, the presence of riming process has a little influence on the surface precipitation because of the small height of the system. The results of the sensitivity tests also suggest that rimed snow aggregates and graupel are overdominant in the default run using MYJ PBL model.

[61] This paper presents a comparative analysis between the remotely sensed and in situ measurements and the highresolutional NWP simulation with one of the most sophisticated microphysical schemes. Detailed discussion on effects of riming process on ice cloud microphysics using the kind of modeling approach has not been well studied as long as we know. This study is an example of great advantage by introducing the advanced cloud microphysics with a gradation of distinct hydrometeor categories to reproduce realistic solid-phase microphysical structure in NWP simulations. The result will be of benefit to the cloud modeling community because it may justify the validity of ideal cloud resolving simulations using similar advanced microphysics previously achieved. Utilizing an up-to-date computational server has enabled the high-cost model calculation and the off-line handling of the output data including PSDs in great volume.

[62] In our investigated cases, the two events were clearly classified from the view of presence or absence of riming process. The condition of the lake-effect case is characterized by the relatively very cold temperature of approximately $-20^{\circ} \mathrm{C}$ at $850 \mathrm{hPa}$ level, which contrasts with the corresponding temperature of approximately $-10^{\circ} \mathrm{C}$ in the synoptic case. This cold temperature may be sufficient condition for the supersaturation with respect to water because of low saturation pressure, but remains to be understood how this snowstorm acts in the absence of supercooled water at warmer temperature. In addition, it is unknown how these distinct snowfall events are influenced by difference in the conditions of aerosols acting as condensation nuclei $(\mathrm{CN})$ and/or ice nuclei (IN). The kind of clouds grew from a fresh water surface in this lake-effect case, whereas similar snowstorms are observed even near ocean where sea salt aerosols are enriched in the air mass with a strong wind, for example, over the coastal region of winter Japan sea [e.g., Tsunogai, 1975].

[63] The change in bulk particle density in the sensitivity simulations did not affect the distribution of surface precipitation in the lake-effect case. However, it plays an important role to determine the radiative properties that have a large influence on the calculation of retrieval algorithms for radar and microwave radiometer measurements. For example, surface precipitation estimated from a radar measurement 
may include a large error when the actual particle density is different from the value assumed in the algorithm for the estimation. Note that this study is involved in the development of the National Aeronautics and Space Administration (NASA) synthetic Global Precipitation Measurement (GPM) simulator project. A purpose of the project is to offer a set of ground validation (GV) constrained 3-D database of WRFSBM output. The database will be used to support testing/ developing the prelaunch precipitation retrieval algorithm for the measurements by GPM core satellites. The simulation result of this study has been integrated into the database as a preliminary result; therefore, hydrometeor particle size and density are important parameters that should be validated using observed data.

[64] There still remains a large uncertainty in ice microphysics modeling including riming process. Recently, a new field campaign was conducted in the same location, so-called GPM Cold-Season Precipitation Experiment (GCPEx). It deployed more and better in situ and remotely sensed instruments to measure characteristics of midlatitude ice cloud microphysics. Case studies based on analyses of the WRF-SBM simulations and the GCPEx observational data sets are subsequently expected.

\section{Appendix A: The 2DVD Correction Used in the Simulator Unit of the Aircraft and Ground-Based Measurements Products}

[65] Snow aggregates are assumed to be spherical shapes in the SBM for the reason that it can simplify the modeling of microphysical processes such as diffusion growth and coagulation. However, maximum dimensions of randomly oriented nonspherical aggregates were observed in the in situ measurements by aircraft 2-D probes and ground-based Parsivel disdrometer. The purpose of the 2DVD-based correction is to statistically convert the spherical diameter assumed in the SBM into maximum lengths, which correspond to be the in situ observables, using the 2DVD data. Note that this correction is applied to the calculation of the aircraft and ground-based measurements in G-SDSU for a diagnostic purpose, not within the WRF-SBM weather prediction simulation.

[66] The technical description of the 2DVD measurement in the C3VP campaign can be found in the work of Huang et al. [2010]. The two line scan cameras in the instrument provide images of a falling particle from orthogonal horizontal angles. The shape parameters of particles such as shadow areas $\left(\mathrm{A}_{1}\right.$ and $\left.\mathrm{A}_{2}\right)$, associated vertical maximum dimensions $\left(\mathrm{H}_{1}\right.$ and $\left.\mathrm{H}_{2}\right)$ and horizontal maximum dimensions $\left(\mathrm{W}_{1}\right.$ and $\left.\mathrm{W}_{2}\right)$, can be obtained from the two snapshots. The apparent volume $\left(\mathrm{V}_{\mathrm{app}}\right)$ and apparent diameter $\left(\mathrm{D}_{\mathrm{app}}\right)$ are defined following equation 1 of Huang et al. [2010] using these shape parameters.

[67] We sampled the set of 2DVD parameters during 2022 January 2007, and estimated the ratios between maximum vertical/horizontal dimensions to the apparent diameters $\left(R_{H}=H / D_{\text {app }}\right.$ and $\left.R_{W}=W / D_{\text {app }}\right)$. These ratios are normalized for a given $D_{\text {app }}$ bins $(0-10 \mathrm{~mm}$ for each $1 \mathrm{~mm}$ bin width), as shown in Figure A1. For example, at $\mathrm{D}_{\text {app }}$ of $6 \mathrm{~mm}$, horizontal maximum dimension ranges from $4.5 \mathrm{~mm}$ to $12 \mathrm{~mm}$ and the mode value is $7.2 \mathrm{~mm}$. A conditional probability density function (PDF) of horizontal maximum

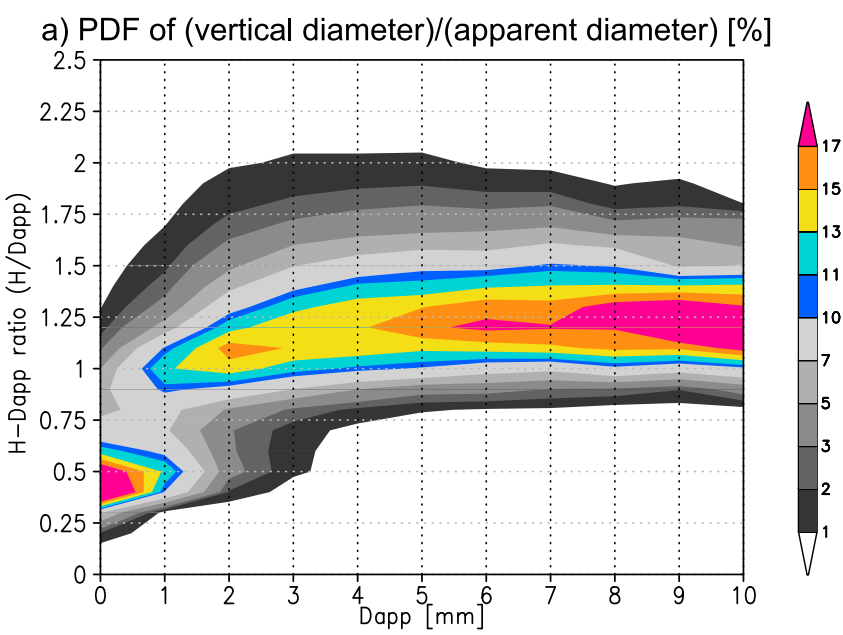

b) PDF of (horizontal diameter)/(apparent diameter) [\%]

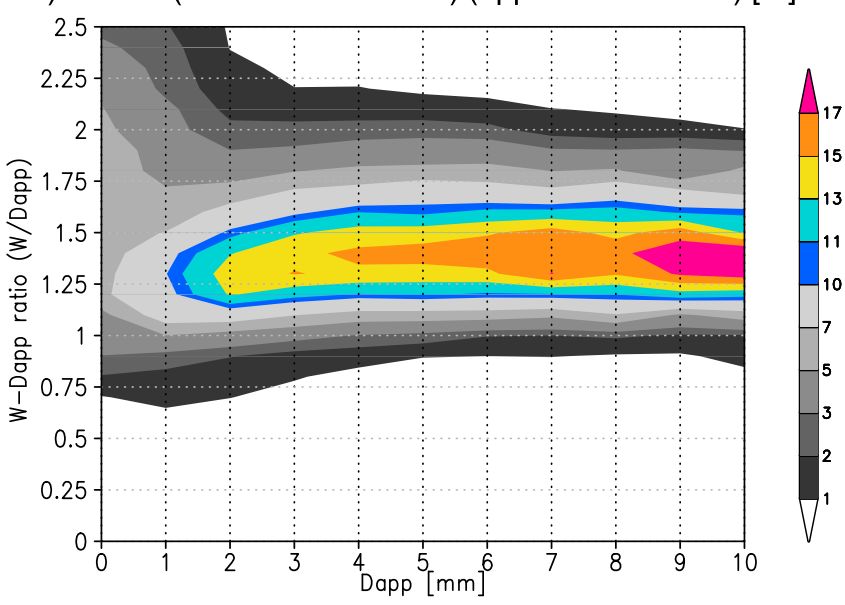

Figure A1. Probability density functions of (a) ratio between the vertical diameter and apparent diameter and (b) ratio between the horizontal diameter and apparent diameter, from the analysis of the two-dimensional video disdrometer (2DVD) ground measurement.

dimension for a given apparent diameter can be approximated to this PDF in Figure A1.

[68] If snow aggregates of the SBM are expanded into randomly oriented nonspherical particles and the original spherical diameter is assumed to be equivalent to $D_{\text {app }}$, the PDFs of the maximum vertical/horizontal dimensions are approximated to those shown in Figure A1. The maximum dimensions are compatible to those actually observed in the ground-based Parsivel measurement and approximated in the aircraft PMS measurement. The PDF between the maximum (of horizontal and vertical) diameter and the apparent diameter is introduced in the calculation of distribution from 43 binned PSD of the SBM to 33 binned PSD of the simulated aircraft PMS measurement. The PDF between the maximum horizontal diameter and the apparent diameter is used in the distribution calculation from 43 binned PSD of the SBM to 32 binned precipitation PSD of the simulated ground-based Parsivel measurement. This correction is 


\section{Sphere assumption for snow in place of using 2DVD correction}

a) Lake-effect, airborne

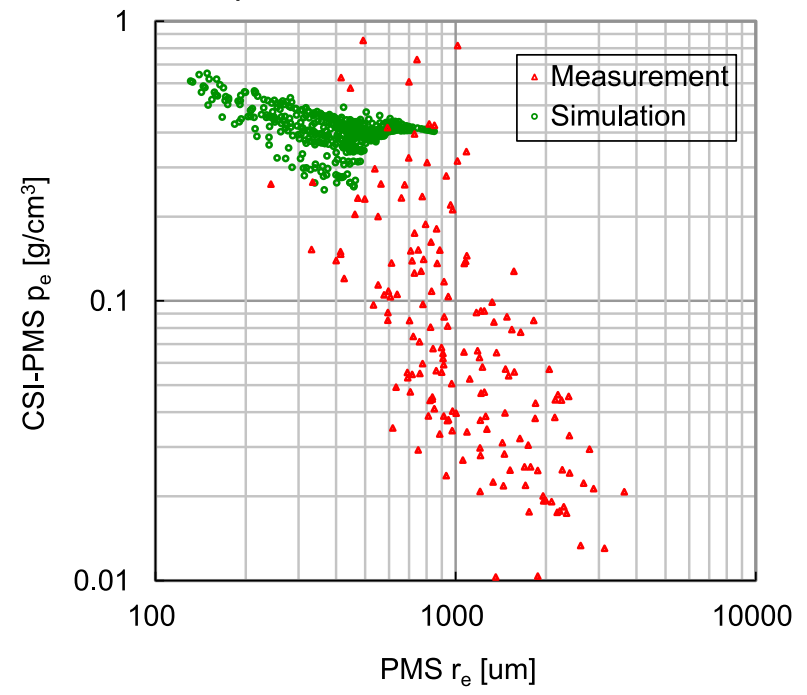

c) Synoptic, airborne

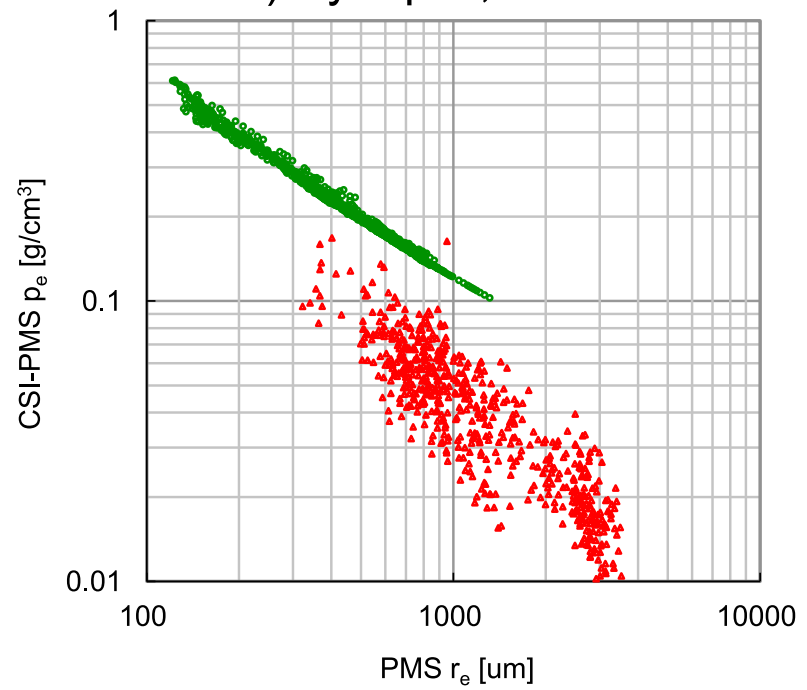

b) Lake-effect, ground

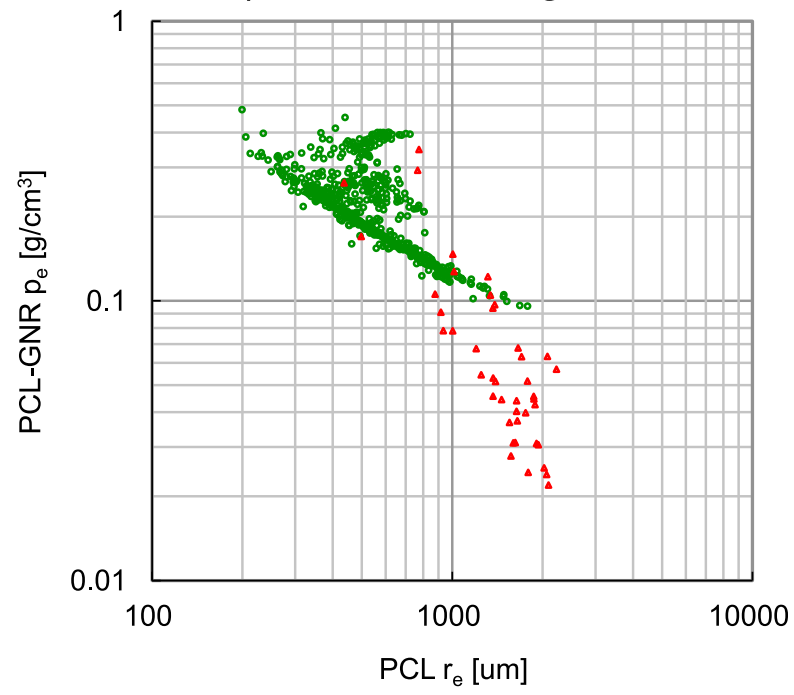

d) Synoptic, ground

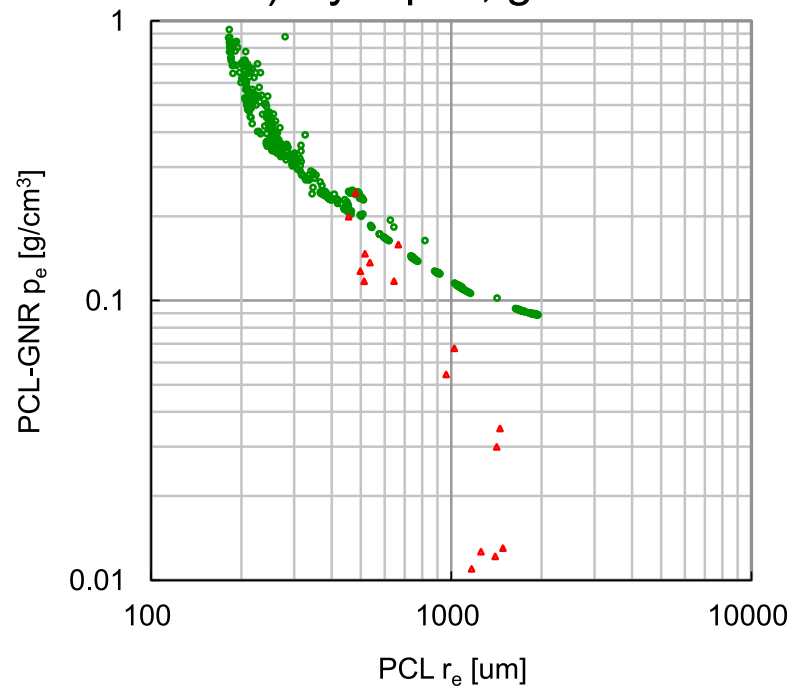

Figure A2. Same as in airborne instrument-based diagrams of Figure 5 but for the simulations without the 2DVD correction.

currently applied only to snow aggregates in the hydrometeor categories of the SBM.

[69] We briefly discuss the influence of the 2DVD correction on the microphysical analysis described in the main part of this paper. Figure A2 shows scatter diagrams of the airborne-based and ground-based $r_{e}-\rho_{e}$ relationships without the 2DVD correction; the set of the corresponding plots using the 2DVD correction is Figure 5. The comparison between Figures 5 and A2 shows that the correction has a large effect on changing the airborne-based composites, whereas little difference is seen in the ground-based composites. As compared with Figures A2a and A2c, the plots in Figures $5 \mathrm{a}$ and $5 \mathrm{c}$ are biased toward larger $r_{e}$ and remarkably smaller $\rho_{e}$. This difference is caused by a shift of PSD toward the larger size side on the 33 bins by replacing the apparent diameter with the maximum diameter in the 2DVD correction. The distinctions between the two cases are still confirmed, but the agreement with the measurement profiles is deteriorated, especially in the airborne composites. This result suggests that the assumption of spherical snow body in the SBM is not appropriate to be directly compared with the airborne or ground-based measurements in this case. The difference in degrees of change between the airborne and ground-based composites is considered to be due to the difference in the PDFs (Figure A1). Note that a large uncertainty still remains in this approach, especially in the PDF part of the small particle of the diameter less than approximately $2 \mathrm{~mm}$ because of the instrumental noise. 
[70] Acknowledgments. This study was supported by the NASA Precipitation Measuring Mission (PMM) and NASA Modeling Analysis Prediction (MAP). One of the authors (A. Khain) is supported by a grant from the Israel Science Foundation (140/07). The authors wish to acknowledge the developers of the WRF and HUCM models.

\section{References}

Battaglia, A., E. Rustemeier, A. Tokay, U. Blahak, and C. Simmer (2010), PARSIVEL snow observations: A critical assessment, J. Atmos. Oceanic Technol., 27, 333-344, doi:10.1175/2009JTECHA1332.1.

Beard, K. V. (1976), Terminal velocity and shape of cloud and precipitation drops aloft, J. Atmos. Sci., 33, 851-864, doi:10.1175/1520-0469(1976) $033<0851$ :TVASOC $>2.0 . \mathrm{CO} ; 2$

Bigg, E. K. (1953), The formation of atmospheric ice crystals by the freezing of droplets, Q. J. R. Meteorol. Soc., 79, 510-519, doi:10.1002/ qi. 49707934207.

Bott, A. (1998), A flux method for the numerical solution of the stochastic collection equation, J. Atmos. Sci., 55, 2284-2293, doi:10.1175/15200469(1998)055<2284:AFMFTN $>2.0$. CO;2.

Brandes, A. E., K. Ikeda, G. Zhang, M. Schonhuber, and R. M. Rasmussen (2007), A statistical and physical description of hydrometeor distributions in Colorado snowstorms using a video disdrometer, J. Appl. Meteorol. Climatol., 46, 634-650, doi:10.1175/JAM2489.1

Chen, J. P., and D. Lamb (1994), Simulation of cloud microphysical and chemical processes using a multicomponent framework. Part I: Description of the microphysical model, J. Atmos. Sci., 51, 2613-2630, doi:10.1175/ 1520-0469(1994)051<2613:SOCMAC $>2.0$.CO;2.

Connolly, P. J., C. Emersic, and P. R. Field (2012), A laboratory investigation into the aggregation efficiency of small ice crystals, Atmos. Chem. Phys., 12, 2055-2076, doi:10.5194/acp-12-2055-2012.

Grell, G. A., and D. Devenyi (2002), A generalized approach to parameterizing convection combining ensemble and data assimilation techniques, Geophys. Res. Lett., 29(14), 1693, doi:10.1029/2002GL015311.

Hallett, J., and S. C. Mossop (1974), Production of secondary ice crystals during the rimming process, Nature, 249, 26-28, doi:10.1038/249026a0.

Hashino, T., and G. Tripoli (2007), The Spectral Ice Habit Prediction System (SHIPS). Part I: Model description and simulation of vapor deposition processes, J. Atmos. Sci., 64, 2210-2237, doi:10.1175/JAS3963.1.

Heymsfield, A. J., and L. M. Miloshevich (1989), An evaluation of liquid water content measuring devices in cold clouds during FIRE, J. Atmos Oceanic Technol., 6, 378-388, doi:10.1175/1520-0426(1989)006<0378: EOLWMI>2.0.CO;2.

Heymsfield, A. J., A. Bansemer, C. G. Schmitt, C. Twohy, and M. R. Poellet (2004), Effective ice particle densities derived from aircraft data, J. Atmos. Sci. 61, 982-1003.

Hong, S.-Y., and H.-L. Pan (1996), Nonlocal boundary layer vertical diffusion in a medium-range forecast model, Mon. Weather Rev., 124, 2322-2339, doi:10.1175/1520-0493(1996)124<2322:NBLVDI >2.0.CO;2.

Hong, S.-Y., Y. Noh, and J. Dudhia (2006), A new vertical diffusion package with an explicit treatment of entrainment processes, Mon. Weather Rev., 134, 2318-2341, doi:10.1175/MWR3199.1.

Huang, G.-J., V. N. Bringi, R. Cifelli, D. Hudak, and W. A. Petersen (2010), A methodology to derive radar reflectivity-liquid equivalent snow rate relations using $\mathrm{C}$-band radar and a $2 \mathrm{D}$ video disdrometer, J. Atmos. Oceanic Technol., 27, 637-651, doi:10.1175/2009JTECHA1284.1

Hudak, D., P. Rodreguez, G. W. Lee, A. Ryzhkov, F. Fabry, and N. Donaldson (2006), Winter precipitation studies with a dual-polarized C-band radar, paper presented at 4th European Conference on Radar in Meteorology and Hydrology, ERAD, Barcelona, Spain.

Iguchi, T., T. Nakajima, A. P. Khain, K. Saito, T. Takemura, and K. Suzuki (2008), Modeling the influence of aerosols on cloud microphysical properties in the east Asia region using a mesoscale model coupled with a binbased cloud microphysics scheme, J. Geophys. Res., 113, D14215, doi:10.1029/2007JD009774.

Janjić, Z. I. (1990), The step-mountain coordinate: Physical package, Mon Weather Rev. 118, 1429-1443, doi:10.1175/1520-0493(1990)118<1429. TSMCPP $>2.0 . \mathrm{CO} ; 2$.

Ji, W., and P. K. Wang (1990), Numerical simulation of three-dimensional unsteady viscous flow past fixed hexagonal ice crystals in the airPreliminary results, Atmos. Res., 25, 539-557, doi:10.1016/0169-8095(90) 90037-D.

Kato, T. (1995), A Box-Lagrangian raindrop scheme, J. Meteorol. Soc. Jpn., 73, 241-245.

Khain, A. P., and I. L. Sednev (1995), Simulation of hydrometeor size spectra evolution by water-water, ice-water and ice-ice interactions, Atmos. Res., 36, 107-138, doi:10.1016/0169-8095(94)00030-H.
Khain, A. P., M. Ovtchinnikov, M. Pinsky, A. Plkrovsky, and H. Krugliak (2000), Notes on the state-of-the-art numerical modeling of cloud microphysics, Atmos. Res., 55, 159-224, doi:10.1016/S0169-8095(00)00064-8.

Khain, A. P., M. B. Pinsky, M. Shapiro, and A. Pokrovsky (2001), Collision rate of small graupel and water drops, J. Atmos. Sci., 58, 2571-2595, doi:10.1175/1520-0469(2001)058<2571:CROSGA > 2.0.CO;2.

Khain, A. P., A. Pokrovsky, M. Pinsky, A. Seifert, and V. Phillips (2004), Simulation of effects of atmospheric aerosols on deep turbulent convective clouds using a spectral microphysics mixed-phase cumulus cloud model. Part I: Model description, J. Atmos. Sci., 61, 2963-2982, doi:10.1175/JAS-3350.1.

Khain, A. P., N. Benmoshe, and A. Pokrovsky (2008), Factors determining the impact of aerosols on surface precipitation from clouds: Attempt of classification, J. Atmos. Sci., 65, 1721-1748, doi:10.1175/ 2007JAS2515.1.

Khain, A. P., L. R. Leung, B. Lynn, and S. Ghan (2009), Effects of aerosols on the dynamics and microphysics of squall lines simulated by spectral bin and bulk parameterization schemes, J. Geophys. Res., 114, D22203, doi:10.1029/2009JD011902

Khain, A., B. Lynn, and J. Dudhia (2010), Aerosol effects on intensity of landfalling hurricanes as seen from simulations with the WRF model with spectral bin microphysics, J. Atmos. Sci., 67, 365-384, doi:10.1175/ 2009JAS3210.1

Khain, A., A. Pokrovsky, D. Rosenfeld, U. Blahak, and A. Ryzhkov (2011), The role of $\mathrm{CCN}$ in precipitation and hail in a mid-latitude storm as seen in simulations using a spectral (bin) microphysics model in a $2 \mathrm{D}$ dynamic frame, Atmos. Res., 99, 129-146, doi:10.1016/j.atmosres.2010.09.015.

Khain, A. P., V. Phillips, N. Benmoshe, and A. Pokrovsky (2012), The role of small soluble aerosols in the microphysics of deep maritime clouds, J. Atmos. Sci., 69, 2787-2807, doi:10.1175/2011JAS3649.1.

Kruger, A., and W. F. Krajewski (2002), Two-dimensional video disdrometer: A description, J. Atmos. Oceanic Technol., 19, 602-617.

Lang, S., W.-K. Tao, R. Cifelli, W. Olson, J. Halverson, S. Rutledge, and J. Simpson (2007), Improving simulations of convective systems from TRMM LBA: Easterly and westerly regimes, J. Atmos. Sci., 64, 1141-1164, doi:10.1175/JAS3879.1.

Lin, Y., and B. A. Colle (2011), A new bulk microphysical scheme that includes riming intensity and temperature-dependent ice characteristics, Mon. Weather Rev., 139(3), 1013-1035, doi:10.1175/2010MWR3293.1.

Lin, Y. H., R. D. Farley, and H. D. Orville (1983), Bulk parameterization of the snow field in a cloud model, J. Clim. Appl. Meteorol., 22, 1065-1092, doi:10.1175/1520-0450(1983)022<1065:BPOTSF $>2.0$. CO 2 .

Lin, Y., L. J. Donner, and B. A. Colle (2011), Parameterization of riming intensity and its impact on ice fall speed using ARM data, Mon. Weather Rev., 139(3), 1036-1047, doi:10.1175/2010MWR3299.1.

Liu, G. (2008), A database of microwave single-scattering properties for nonspherical ice particles, Bull. Am. Meteorol. Soc., 89, 1563-1570, doi:10.1175/2008BAMS2486.1.

Löffler-Mang, M., and J. Joss (2000), An optical disdrometer for measuring size and velocity of hydrometeors, J. Atmos. Oceanic Technol., 17, 130-139, doi:10.1175/1520-0426(2000)017<0130:AODFMS $>2.0$.CO;2.

Lynn, B. H., A. P. Khain, J. Dudhia, D. Rosenfeld, A. Pokrovsky, and A. Seifert (2005a), Spectral (bin) microphysics coupled with a mesoscale Model (MM5). Part I: Model description and first results, Mon. Weather Rev., 133(1), 44-58, doi:10.1175/MWR-2840.1.

Lynn, B. H., A. P. Khain, J. Dudhia, D. Rosenfeld, A. Pokrovsky, and A. Seifert (2005b), Spectral (bin) microphysics coupled with a mesoscale model (MM5). Part II: Simulation of a CaPE rain event with a squall line, Mon. Weather Rev., 133(1), 59-71, doi:10.1175/MWR-2841.1.

Masunaga, H., and C. D. Kummerow (2005), Combined radar and radiometer analysis of precipitation profiles for a parametric retrieval algorithm, J. Atmos. Oceanic Technol., 22, 909-929, doi:10.1175/JTECH1751.1.

Masunaga, H., T. Matsui, W.-K. Tao, A. Y. Hou, C. D. Kummerow, T. Nakajima, P. Bauer, W. S. Olson, M. Sekiguchi, and T. Y. Nakajima (2010), Satellite data simulator unit: A multisensor, multispectral satellite simulator package, Bull. Am. Meteor. Soc., 91, 1625-1632, doi:http://dx. doi.org/10.1175/2010BAMS2809.1.

Matsui, T., X. Zeng, W.-K. Tao, H. Masunaga, W. Olson, and S. Lang (2009), Evaluation of long-term cloud-resolving model simulations using satellite radiance observations and multifrequency satellite simulators, J. Atmos. Oceanic Technol., 26, 1261-1274, doi:10.1175/ 2008JTECHA1168.1

Matsui, T., T. Iguchi, X. Li, and W.-K. Tao (2010), Development of the synthetic GPM simulator, paper presented at NASA PMM meeting, NASA, Seattle, Wash., 1-5 Nov.

Meyers, M. P., P. J. DeMott, and W. R. Cotton (1992), New primary icenucleation parameterizations in an explicit cloud model, J. Appl. 
Meteorol., 31, 708-721, doi:10.1175/1520-0450(1992)031<0708:NPINPI> 2.0. $\mathrm{CO} ; 2$.

Misumi, R., et al. (2010), Microphysical structure of a developing convective snow cloud simulated by an improved version of the multidimensional bin model, Atmos. Sci. Lett., 11, 186-191, doi:10.1002/ asl.268.

Monin, A. S., and A. M. Obukhov (1954), Basic laws of turbulent mixing in the surface layer of the atmosphere (in Russian), Contrib. Geophys. Inst. Acad. Sci., 24(151), 163-187.

Morrison, H., and W. W. Grabowski (2008), A novel approach for representing ice microphysics in models: Description and tests using a kinematic framework, J. Atmos. Sci., 65, 1528-1548, doi:10.1175/2007JAS2491.1.

Morrison, H., and W. W. Grabowski (2010), An improved representation of rimed snow and conversion to graupel in a multicomponent bin microphysics scheme, J. Atmos. Sci., 67, 1337-1360, doi:10.1175/ 2010JAS3250.1.

Ovtchinnikov, M., and Y. L. Kogan (2000), An investigation of ice production mechanisms using a 3D cloud model with detailed microphysics. Part I: Model description, J. Atmos. Sci., 57, 2989-3003, doi:10.1175/ 1520-0469(2000)057<2989:AIOIPM>2.0.CO;2.

Phillips, V., A. Khain, and A. Pokrovsky (2007), The influence of melting on the dynamics and precipitation production in maritime and continental storm-clouds, J. Atmos. Sci., 58, 742-764.

Pinsky, M., A. Khain, and M. Shapiro (2001), Collision efficiencies of drops in a wide range of Reynolds numbers: Effects of pressure, J. Atmos. Sci., 58 , 742-764, doi:10.1175/1520-0469(2001)058<0742:CEODIA $>2.0$.CO;2.

Pruppacher, H. R., and J. D. Klett (1997), Microphysics of Clouds and Precipitation, 2nd ed., 914 pp., Oxford Univ. Press, New York.
Rasmussen, R. M., and A. J. Heymsfield (1987), Melting and shedding of graupel and hail. Part I: Model physics, J. Atmos. Sci., 44, 2754-2763, doi:10.1175/1520-0469(1987)044<2754:MASOGA>2.0.CO;2.

Rogers, R. R., and M. K. Yau (1989), A Short Course in Cloud Physics, 3rd ed., 293 pp., Pergamon, Oxford, U. K.

Shi, J. J., et al. (2010), WRF simulations of the 20-22 January 2007 snow events over eastern Canada: Comparison with in situ and satellite observations, J. Appl. Meteorol. Climatol., 49, 2246-2266, doi:10.1175/ 2010JAMC2282.1.

Takahashi, T., T. Endoh, and G. Wakahama (1991), Vapor diffusional growth of free-falling snow crystals between -3 and $-23^{\circ} \mathrm{C}, \mathrm{J}$. Meteorol. Soc. Jpn., 69, 15-30.

Tao, W.-K., and J. Simpson (1993), The Goddard Cumulus Ensemble model. Part I: Model description, Terr. Atmos. Oceanic Sci., 4, 19-54.

Tao, W.-K., et al. (2003), Microphysics, radiation and surface processes in the Goddard Cumulus Ensemble (GCE) model, Meteorol. Atmos. Phys. 82, 97-137, doi:10.1007/s00703-001-0594-7.

Tsunogai, S. (1975), Sea salt particles transported to the land, Tellus, 27, 51-58, doi:10.1111/j.2153-3490.1975.tb01654.x.

Twohy, C. H., A. J. Schanot, and W. A. Cooper (1997), Measurement of condensed water content in liquid and ice clouds using an airborne counterflow virtual impactor, J. Atmos. Oceanic Technol., 14, 197-202, doi:10.1175/1520-0426(1997)014<0197:MOCWCI >2.0.CO;2.

Wang, P. K., and W. Ji (1997), Numerical simulation of three-dimensional unsteady flow past ice crystals, J. Atmos. Sci, 54, 2261-2274, doi:10.1175/1520-0469(1997)054<2261:NSOTDU>2.0.CO;2. 